\title{
1 \\ Financial Crises and EU Credit Access Policy
}

Francesco Minnetti, Pasqualina Porretta and Ervin Sinani

\subsection{Methodology and purposes of the research}

The European Commission's proposals for the 2014-2020 legislative framework aim to increase the flexibility of the regulation, taking into account national and sectorial peculiarities; they further seek to improve the coherence and consistency between instruments, raise visibility and transparency and reduce the number of instruments in order to ensure a sufficient critical mass in a context where the amount of funding available is scattered across a large number of regions and recipients. ${ }^{1}$

Moreover, the European Commission attributes increasing importance to the use of financial engineering instruments, which are considered a more efficient and viable alternative to traditional grant-based financing. In fact, one of the main targets of the European Commission is to improve the level of knowledge that European resource management authorities should possess on financial engineering instruments (European Parliament, 2013, Financial Engineering Instruments in Cohesion Policy). The use of financial engineering instruments is an innovative way of spending the EU budget, in addition to grants and subsidies. In fact, under the cohesion policy, structural funds (SF) have typically been allocated to beneficiaries (organisations or projects) through (non-repayable) grant funding in order to achieve the objectives and outcomes defined in the national or regional operational programmes (OPs) priorities.

The literature and field research helped identify the main advantages of using financial engineering instruments: leverage effect, sustainability, capacity building, risk coverage, speeding up programme implementation, promoting urban development. 
However, in the programming period 2007-2013, the managing authorities (MAs) increased the use of the structural funds through commercial practices in the form of equity, loans or guarantees (operated on a repayable basis, unlike grants), although the diffusion of financial instruments is again limited to a specific sector. Many of these instruments are designed to improve the financial sustainability of microfinance/microcredit schemes that can be pursued also by way of market-oriented instruments (such as securitisation and structured finance).

Microcredit, and microfinance in general, can be seen as a political tool in some countries, where politicians often intervene in favour of individuals who struggle to repay loans during times of economic stress. Microfinance can be an appropriate solution against financial and social exclusion by ensuring the availability of suitable loans, savings and other financial products or services. The EU has set up several policies that address social inclusion and highlight the efficacy of microloans in reducing poverty, boosting economic growth and increasing job creation.

In this perspective, we should keep in mind that while "there is no internationally accepted definition of microfinance", the term is generally used to indicate a range of financial services/products (of small amounts) offered to low-income/non-bankable customers and microenterprises. Microfinance targets those individuals who are denied credit by formal financial and banking institutions because of financial illiteracy or lack of knowledge of the formal rules that they should follow to access credit provided by these institutions (Leone and Porretta, 2014, p. 1).

Microfinance covers a wide range of financial services; while it is often confused with microcredit, the latter is actually just one of the products in microfinance (albeit the most important), which includes also a number of other financial products/services that can be synthetically grouped in the following areas: small loans (microcredit), microinsurance products/services, microleasing instruments/products, social housing products/services, forms of deposit collection and management, payment services, remittance services.

Over the past decade, the microfinance universe has undergone several changes (Leone and Porretta, 2014, p. 4). Generally, microfinance is associated with developing countries, where large segments of population need to access these types of financial services; however, microfinance includes a number of activities that extend to developed countries too, where - especially after the international economic and 
financial crisis - an increasing number of people deal with poverty issues due to factors such as immigration, unemployment, inactivity and marginalisation.

By "microcredit" we refer here to "microcredit for businesses/entrepreneurs", although the term is normally used to designate two types of financial activities: the so-called social microcredit (mainly aimed at social inclusion of excluded subjects through the provision of financial support to their current expenditure as well as social services, training courses, etc.) and microcredit for businesses (supporting start-ups and self-employment initiatives), which obviously has different goals. The traditional microcredit target groups are highly risky and cost-intensive; as a result, commercial banks are not interested in catering to some customer segments, which thus end up being non-bankable. This means that the microcredit business is quite different from traditional banking. It includes innovative and customised elements such as different collateral requirements or no collaterals at all, as well as alternative methods for creditworthiness assessment. In many cases, microcredit is granted not only for economic reasons and/or to make a profit but also to serve a broader purpose of social cohesion by trying to reintegrate disadvantaged people into their communities (Leone and Porretta, 2014). In fact, different kinds of credit guarantee schemes, usually created with EU structural fund, support microcredit initiatives in several EU countries.

As is known, under the programming period 2014-2020 of the EU structural funds, the role of the European Social Fund (ESF) is further enhanced, in the attempt to promote social inclusion and prevent and fight poverty, through the mobilisation of a number of policies dedicated to economically and socially disadvantaged individuals. Among the latter, there are longterm unemployed, people affected by disabilities, migrants, ethnic minorities - as well as new sectors of the society, such as women, young couples, single-parent families - who, until a few years ago, enjoyed conditions far from what today are perceived as severe social risks. The current economic crisis has severely hit the Italian economy and prompted policymakers to implement public policies focusing on the increasing risk of social disintegration, which is leading large sectors of the population towards a deterioration of the conditions to access fundamental citizenship rights, such as employment, housing, a satisfactory social life, territorial mobility and new technology. The need to prevent further social inequalities strongly calls for improved public policies able to identify the needs of the European population, especially those segments at risk of social exclusion, and thus implement instruments and programmes to meet such needs, starting from a solid and shared idea of European social citizenship. To support 
this pattern of growth, national and local government authorities should be equipped with intervention instruments characterised by a greater flexibility, customisable, integrated and easy to access, which, on one side, can effectively reach out to the growing number of disadvantaged subjects and, on the other, may benefit from the increased expertise of the public administration to be channelled and governed within innovative strategies and practices. To this end, the MAs must possess an efficient capacity to plan and organise the European resources; in our opinion, such capacity should originate from a detailed knowledge of local issues and requirements as well as increased information on: EU cohesion policy, thematic objectives, types and features of EU structural funds and other instruments introduced by the European Commission, financial engineering instruments that can be activated and supported by these European financial resources, characteristics of the microfinance business.

In this perspective, this editorial project developed by the Italian National Public Agency for Microcredit ${ }^{2}$ within the project "Capacity Building" 3 focuses on the capacity building of public managing authorities (in relation to structural funds) also with regard to the microcredit sector. The study aims to provide a clear picture of the European managing authorities' capacity building also with regard to the microcredit sector in the current scenario, as well as identify best practices and perspectives in this sector.

In our opinion, it is particularly interesting to examine the principal guidelines of the EU cohesion policy, the EU financial instruments in the new regulatory framework and how structural funds have been managed and used so far by policymakers in the European convergence regions with regard to the microcredit sector. Selected case studies on a specific topic will provide a better idea of the scope of this work.

Moreover, this study aims to highlight, through two surveys, strengths and weaknesses of the MAs' capacity building as well as formulate a number of strategic and operational recommendations on the use of the structural funds in the microfinance sector, in the context of ongoing planning processes regarding the implementation of financial instruments in the programming period 2014-2020 (cohesion policy).

In this perspective, this book aims to investigate and provide an answer to the following questions:

- What uses can be made of structural funds and what are their operational features?

- What are the financial instruments used under the EU 2007-2013 regulatory framework? 
- What are the new financial instruments available under the new programming period (2014-2020)? What are the goals and differences compared to the previous regulatory framework?

- What are the capacity building requirements related to financial instruments in the new EU regulatory framework (2014-2020)?

- What are the microcredit instruments available under the new EU regulatory framework (2014-2020)?

- What are the main operational features of the microcredit programmes activated thanks to the EU structural funds?

- What are the main results achieved by the microcredit programmes activated thanks to the EU structural funds?

- What are the strengths and weaknesses of the managing authorities' capacity building in the EU convergence regions?

- What are the perspectives of the microcredit activities to be supported by the EU structural funds in the ongoing planning processes with regard to the implementation of financial instruments in the programming period 2014-2020?

The methodological approach of this research is based on three separate "tools":

1. A review of the EU regulatory framework on microcredit instruments in the 2014-2020 cohesion policy.

2. Selected case studies on specific topics (non-financial services, housing microcredit, etc.) related to some countries (Italy, France, Germany).

3. Two questionnaires concerning the managing authorities' capacity building in the microcredit sector and their capacity building in relation to financial instruments in the new EU regulatory framework.

This study is divided into two parts and five chapters; they are briefly described below.

In this chapter, after the introduction of the aims and the methodology of the research, we provide an introduction to trends and perspectives of credit and finance for the SMEs in Europe during the financial crisis as well as an overview on a number of EU financial instruments (EIB, EIF and other initiatives). In the context of the financial crisis, microenterprises generally play a crucial role in fostering economic dynamism in the regional and national economic systems by stimulating competitiveness and productivity. Access to finance is a well-recognised problem in the current context. Access of microenterprises to finance has become 
increasingly difficult, especially in times of recovery from the economic downturn. In this perspective, the chapter offers some considerations on the use of EU instruments to support microenterprises in gaining access to credit explain why those instruments may be used, in the current scenario, in the small and micro enterprises.

In Chapter 2, "EU Cohesion Policy and Microfinance", the reader is given an insight into the main features of the cohesion policy, EU structural funds and the financial engineering instruments: regulatory framework and operational features under the programming periods 2000-2006 and 2007-2013. The chapter outlines advantages and disadvantages in the use of financial instruments as well as the new EU regulatory framework (Horizon 2014-2020); it offers also a comparative analysis with the previous regulatory framework. Finally, it examines the role of the structural funds with regard to microfinance.

The third chapter, "EU Financial Engineering and Microfinance Non-financial Service: A Case Studies", focuses on non-financial services in the microcredit sector: the use of European funds to support nonfinancial services, advantages and operational features. The non-financial services, usually named business development services (BDS), traditionally associated with the provision of microfinance services (microcredit, microguarantee, microinsurance, etc.) are aimed to assist the microcredit borrowers, potential and existing entrepreneurs, to overcome difficulties in the appropriate use of the financial products contracted. They are also a useful tool to start and/or develop their income-generating activities and/or businesses. Operational features of a non-financial service offered in some European countries are analysed through a number of selected case studies (Romania, Italy).

In the fourth chapter, "Microfinance and Capacity Building in the EU Policy", we present the role of the National Agency for Microcredit in the EU Capacity Building project. In particular, we introduce the main issues of the Capacity Building project managed by ENM with regard to microleasing, microinsurance and microcredit for social housing. For each of these financial instruments, we try to explain their main operational features as analysed during the aforementioned project.

The second part of the book is dedicated to MAs' capacity building surveys; in the fifth chapter, "Capacity Building Surveys", we present the methodology and the questionnaires used in the survey. We provide an explanation of objectives and structure (investigation area) of the questionnaires, the main content of each investigation area and the selected survey sampling of the convergence regions involved. 
The first questionnaire ("The managing authorities' interest and needs in capacity building activities") focuses on three investigation areas dedicated respectively to

- the managing authorities' interest in capacity building activities;

- capacity building area where support is needed;

- types of support activities.

The second questionnaire ("The capacity building of managing authorities in the microcredit sector") focuses on four key investigation areas dedicated respectively to

- analysis of the main results of the microcredit/microfinance programming activity;

- target groups and other operational features;

- monitoring and reporting activities;

- regulatory framework of the microcredit/microfinance sector and others.

This chapter also illustrates the survey sampling. Finally, it offers an outlook on the perspectives of the programming activities for the microcredit sector with the use of EU structural funds in the context of ongoing planning processes with regard to the implementation of financial instruments in the programming period 2014-2020 (Horizon); it also suggests actions and strategies to be followed in promoting the development of sustainable forms of microcredit by managing authorities in the convergence regions in Europe.

\subsection{Small businesses and microenterprises in the EU economy: introduction}

Small and medium-sized enterprises (SMEs) constitute the connective fabric of the European economy, as they represent its backbone and the true driving force in terms of turnover and employment. Their relevant, structural and strategic importance has contributed to shape a number of development policies promoted by European institutions whose efforts, in recent years in particular, are directed towards increasing their competitiveness on other international markets.

Within the SMEs' world, a considerable role is played by microenterprises; namely, small businesses employing ten people or less and characterised by a turnover below $€ 2$ million. ${ }^{4}$ They represent by far the most 
widespread type within the SME macrogroup and have shown a remarkable capacity of adaptation in times of economic crises and cyclic slowdown, taking advantage of their quick decisional capacity and operational flexibility to face the new general and economic conditions as well as the changes in their reference markets. Yet as is widely known, microenterprises are also affected by some critical elements hindering their growth and development; such criticalities, if not timely addressed, might jeopardise all policies that are aimed, in various forms, at supporting them. One of the most critical aspects, as will be illustrated, concerns their financial profile, a recurring issue affecting the whole category of small and medium-sized enterprises (SMEs), which often relegates them only to forms of self-financing and at the same time is characterised by the absence or insufficient provision of external capital.

To overcome these problems, European institutions have put much effort in stimulating the adoption of a number of financial measures and, within the sector, have actively supported microfinance instruments.

We would like to stress that while there is no internationally accepted definition of microfinance, this term is generally used to indicate an array of financial services/products (of small amounts) offered to low-income/ non-bankable customers and microenterprises. Microfinance thus covers a variety of financial services, including savings, credit, insurance and remittance, and targets those subjects who are usually denied credit by formal financial and banking institutions due to their lack of awareness as well as stringent formal regulations, which they necessarily must abide by in order to access credit from the traditional commercial circuit. ${ }^{5}$ In other words, microfinance, through a number of measures generally characterised by small amounts and reasonable costs, is able to support the most needy individuals as well as entrepreneurs struggling to create or keep their businesses afloat, in particular relying on the responsibility and commitment of the lenders, thus allowing for the development of local economies where such businesses are located. Traditionally, individuals who benefit from microfinance are citizens living in developing countries who struggle to provide for themselves - those unfortunately known as "the poorest of the poor". Within this category, women are of particular significance, since they constitute the group mostly affected by financial exclusion in several developing countries. More recently, microfinance has turned its attention also to self-employed workers and individuals in charge of small and often family owned businesses, who are unable to obtain bank credit. For microentrepreneurs, microfinance represents instead an alternative to borrowing from banks and often constitutes a way out of the moneylending system (La Torre and Vento, 2006, p. 3). 
This first part of the study intends to present an overview of the typical profiles of the European SMEs, in particular focusing on their finance, which is assuming an increasingly crucial role in strengthening their management balance and determining their competitiveness in the market; in addition, this research provides a number of considerations specifically dedicated to microenterprises, as they are by far the most significant component within the broader group of the small businesses. To this end, Section 1.3 herein describes the main distinctive features of small and medium-sized enterprises, offering also a brief representation of a number of aggregates of their positioning within the general economic system in Europe. Section 1.4 focuses on the financial aspects that characterise such enterprises, including their limits and constraints, with particular attention to their relationship with the banking system, which - as will be examined in Section 1.5 - has grown increasingly problematic in recent years due to the effects of the financial and economic crisis and the credit crunch, which affected all business sectors in several EU member countries. Finally, Section 1.6 presents some summary reflections on possible financial measures and interventions to support SMEs, in general, and, more specifically, microenterprises.

\subsection{The importance of the SMEs in the European economy}

As previously mentioned, the SMEs constitute the bulk of European enterprises and play a particularly important role in terms of turnover and employment, contributing to the global competitiveness of national economies as well as to the development of innovation processes. As this macrocategory includes a wide range of businesses, we have decided to lay out some general considerations applicable to them all and then focus specifically on the microenterprises sector, which represents the area of investigation of this work.

The scientific literature unanimously acknowledges the importance played by SMEs in the economic and social fabric of nations (Keeble and Wilkinson, 1999; O'Donnell et al., 2002; Floyd and McManus, 2005; Lukacs, 2005), pointing out that:

- Proportionally, their economic significance is greater than their size and constitutes the main drive behind the creation of jobs (Caree and Klomp, 1996; Davis et al., 1996).

- They are one of the main vehicles for the creation and dissemination of innovation, especially when entrepreneurs show a strong propensity for entrepreneurship and are able to transfer their entrepreneurial 
culture into their businesses, specifically in those sectors characterised by knowledge-intensive and high-added-value productions such as computing or biotechnology ${ }^{6}$ (Edwards et al., 2005; Massa, 2008; Vrande et al., 2008; Love and Roper, 2013).

- They have the capacity of exploiting the synergies offered by the territory, given the greater flexibility of their operational structure and the competitive advantage gained by establishing profitable relations with local universities and research centres.

Whereas the presence of a high number of SMEs is a necessary requirement to strengthen the competitiveness of national economies, it is not a sufficient condition; their potential, in fact, can only be fully exploited if adequate policies to promote their growth and development are put in place; other important factors are the characteristics of the sectors they operate in and their distribution within the broader economic system (Symeonidis, 1996; Kuman et al., 1999; Cabral and Mata, 2003; Nunes et al., 2013).

First of all, it is necessary to properly understand the concept of SME, as the category includes types of businesses with totally different features and requirements. In fact, there are both enterprises operating at a local or national level and businesses boasting a strong international vocation; enterprises that cover the whole supply chain and others specialised only in some specific products; enterprises having internationally renowned brands and enterprises that make a private label their main commercial channel; companies targeting end consumers and others that operate only on a B2B basis; enterprises that introduce effective management tools and methods and others that carry on their business by relying exclusively on intuition and experience. From this variety of models and businesses inevitably arise different needs and requirements in terms of know-how development, investments and priorities to be addressed in order to continue developing their capacity and exploit new business opportunities.

To this end, the aforementioned EC Recommendation no. 1442 of 6 May 2003 - while pointing out that all entities involved in an economic activity should be regarded as enterprises, regardless of their legal status - has defined the following requirements for the categories of small, medium and microenterprises (Table 1.1).

As already mentioned, microenterprises represent the most relevant group within the macrocategory of SMEs, both in terms of employment and turnover; this is also the reason why institutions, operators and academics have turned their attention to their development in recent years. For some 
Table 1.1 Small business definition

\begin{tabular}{lccc}
\hline Type of enterprise & $\begin{array}{l}\text { Number of } \\
\text { employees }\end{array}$ & $\begin{array}{l}\text { Turnover } \\
(€ \text { millions) }\end{array}$ & $\begin{array}{l}\text { Total value of } \\
\text { balance sheet } \\
\text { (€ millions) }\end{array}$ \\
\hline Medium & 250 & 50 & 43 \\
Small & 50 & 10 & 10 \\
Microenterprise & 10 & 2 & 2 \\
\hline
\end{tabular}

Source: Authors' elaboration of European Commission Recommendation (2003) Commission Recommendation of 6 May 2003 concerning the definition of micro, small and mediumsized enterprises (notified under document number C(2003) 1422), Official Journal of the European Union, http://eur-lex.europa.eu/legal-content/EN/TXT/PDF/?uri=CELEX:32003H03 $61 \&$ from $=$ IT.

time now, an emerging doctrine has disputed the positions of that school of thought that saw only large companies and corporations at the core of any economic system, regarding them as the only subjects having the capacity to compete on international markets and able to achieve economies of scale and certain levels of productivity, while considering small and medium-sized enterprises as a limit to the system's economic development. According to this theory, the paradigm is especially true in those countries whose economic systems are mainly based on the SMEs. More specifically, since the 1990s, several countries started to rethink the "myth" of the large corporation (Cameron, 1994; Dowgherty and Bowman, 1995; Baily et al., 1996; Ryan and Macky, 1998; Mirabal and De Young, 2005; Gandolfi and Neck, 2007) and acknowledged instead the growing socio-economic role played by the SMEs. As a matter of fact, this trend was facilitated by the concomitant occurrence of a number of key factors:

- The organisational crisis of large companies, determined by their excessive bureaucratisation and resulting in a consequent and progressive loss of motivation and productivity.

- The abandonment of the vertical integration in the productive process, through the identification and preservation of the core business, the central activity characterised by high added value and outsourcing of all other phases of production.

- The diversification of productive activities, specifically the advent in the market, due to the prevalence of financial management over production, of large groups and corporations in areas of business that are totally different from their products and/or services, which has often led to a decay of their core business. 
- A reduction of scale economies and, therefore, of the minimum production levels for the various industrial compartments.

- The creation of new businesses characterised by small size and high added value.

At the end of the 1990s, when in particular the importance of the role played by the small enterprises in terms of job creation was definitely acknowledged by all member countries, EU institutions started to modify their policies and legislation to support this sector.

The importance of the micro- and small-sized enterprises is sustained by many points of view. It has been argued that a dynamic and growing micro- and small-sized enterprise sector can contribute to the achievement of a wide range of development objectives, including the attainment of income distribution and poverty reduction (DFID, 2000); creation of employment (Daniels, 1999); provision of the seedbed of industrialisation (Grosh and Somolekae, 1996); savings mobilisation (Beck et al., 2005a) and production of goods and services that meet the basic needs of the poor (Cook and Nixson, 2005). In general, microand small-sized enterprises are seen as an integral component of the informal sector in most developing countries. In the majority of cases, these enterprises are initially informal, but some of them survive and gradually turn into formal businesses, thereby providing the foundations of modern private companies (Mkandawire, 1999). Hence, their growth is part and parcel of a dynamic process in the corporate sector, as asserted by Prasad et al. (2005).

In recent years, increased knowledge of the micro- and small-sized enterprises system has improved and a number of basic databases have been made available for empirical studies aimed at identifying the constraints hindering their growth and development (Levy, 1993). According to such researches, the main factors inhibiting their development are represented by limited access to finance, poor managerial skills, lack of training opportunities and high input costs. Significantly, further studies, especially those conduced in the late 1990s and thereafter, suggested that finance represents the main obstacle for the whole micro- and small-sized enterprise sector (Green et al., 2002).

From a theoretical perspective, we have different paradigms. The main proposition, which goes back to the seminal work by Lewis (1955), goes under the name of labour supply theory, according to which the driving force behind micro- and small-sized enterprises is an excess of labour supply that cannot be absorbed by the public sector or large private enterprises. Arguably, the micro- and small-sized 
enterprises sector develops as a response to the growth in unemployment, functioning as a place of last resort for those subjects who are unable to find employment in the formal sector. In this sense, microand small-sized enterprises are expected to grow in periods of economic crisis, whereas the formal sector contracts or grows too slowly to absorb the labour force in excess. The second scientific thesis is the so-called output-demand theory, which postulates that the existence of a market for their products and services is a prerequisite for the development of micro- and small-sized enterprises. Consequently, these companies tend to develop a cyclical relationship with the economy as a whole. The third investigation, known as firm-growth theory, asserts that as a result of industrialisation and economic growth, micro- and small-sized enterprises are likely to disappear and be replaced by modern large-scale industries. This theory, however, proved to be inaccurate, as micro and small enterprises normally do not compete directly with large companies; on the other hand, they often tend to retain their micro and small dimensions and coexist with large multinational businesses. Generally, although each of the aforementioned theories has developed into some variants, they all share the belief that the development and growth of micro- and small-sized enterprises can significantly contribute to poverty reduction.

From an operational standpoint, microenterprises give birth to their own peculiar management and behavioural model (Liedholm and Mead, 1999; Hillary, 2004; Barricelli and Russo, 2005), and only by analysing it can we fully understand and examine their specific nature and propose effective measures and solutions aimed at supporting them.

One of the most relevant aspects here, shared also by other types of SMEs, is the central role played by the entrepreneurs, who often represent the main driver and decisional force behind the business, besides the main engine of any form of strategic innovation. This model is characterised by quick-decision-making capacity and operational flexibility; ${ }^{7}$ conversely, it can be affected by situations in which decisions must be taken on unfamiliar issues or situations, where entrepreneurs and their collaborators do not possess specific and adequate skills and know-how. The second peculiar feature of microenterprises, as a direct consequence of the first, lies in their organisational structure, which in most cases is poorly articulated and shows a preference for a centralised organisational model, reflected in both their communication and management style, where entrepreneurs are often involved in all aspects of the business, often ignoring specific management elements and the importance of developing internal skills and 
competences. This model is also often characterised by the overlapping, in various forms and degrees, of business and family dimension, which may translate into "confusion" in terms of assets, resources and management methods. A further characteristic of microenterprises is given by their limited range of operations, often restricted to narrow, highly competitive markets; as a result, smaller companies tend to limit their strategies with regard to their space of business, the geographical area, the range of products on offer and the degree of vertical integration, moving towards highly focused strategic choices. Finally, as several microenterprises are interconnected and part of industrial clusters or company networks (Parkhe, 2006; Cafaggi, 2011; Gronum et al., 2012), in order to define their positioning it is necessary also to examine the intrinsic elements of their reference networks, markets or supply chain.

Whereas the life cycle of microenterprises is articulated in the classic business phases (creation, development, maturity and obsolescence), within their group we can distinguish those referred to as topo by physician-economist David Birch of MIT (Boston); namely, small enterprises created not to develop themselves but uniquely to generate income and alternative forms of employment and, therefore, destined to retain their small dimension, from the so-called gazelle enterprises (Henrekson et al., 2010), which are small enterprises created with the intent to grow and develop into larger companies, leveraging on their capacity to quickly grab the business opportunities available and sail through periods of crisis and uncertainty, including their capacity to compete on international markets. ${ }^{8}$

According to the extensive literature on the subject (Pal and Ferrando, 2010; EU, 2010; Artola and Genre, 2011; Coluzzi et al., 2012; OECD, 2012, 2013; Hessel and Parker, 2013), besides poor managerial skills and educational background of the entrepreneurs, the growth and development of microenterprises can be hindered by three other obstacles, which represent also their main weaknesses:

- Lack of capital or financial reserves to cope with unexpected events and the difficulty to access credit or bank loans, especially for smaller enterprises unable to offer any collaterals or that have already secured pre-existing assets to obtain financing and, therefore, are already heavily exposed and/or indebted towards banks.

- Lack of a skilled workforce, including the difficulty of training and turning generic labour into specialised work and relocating the workers already employed.

- Bureaucracy, complexities and lengthy of administrative procedures. 
In light of the above considerations, the European Commission has long focused on the development of policies specifically dedicated to the SMEs and microenterprises through a number of programmes and regulations, which are considerably different from the measures applicable to large businesses, as the two types clearly show different features, economic characteristics, requirements and perspectives. Following this logic analysed in detail in Chapter 2 - several measures and programmes were recently started to enhance the competitiveness of the European SME system in different management areas, in particular with regard to the access to credit and the capacity to attract financial resources and investments as well as training programmes to build technical and managerial skills, within a framework that favours the simplification and implementation of specifically targeted solutions. The empirical feedback to the aforementioned considerations and the importance of the microenterprises on the European area is summarised in the charts and tables below.

From a quantitative point of view (Table 1.2), at 31/12/2012, over 20 million SMEs operate in the European economy. Most of them (over 18.7 million) are microenterprises, which represent 92 per cent of the total number of businesses in Europe.

The SMEs make a significant contribution in terms of employment. They employ 66.5 per cent of the total number of workers, with a relevant role played by microenterprises, which employ 28.7 per cent of workers in Europe, a little less than a third of the total.

Table 1.2 Enterprises, employment and gross value added of SMEs in the EU-27, 2012

\begin{tabular}{|c|c|c|c|c|c|c|}
\hline 2012 & Micro & Small & Medium & SMEs & Large & Total \\
\hline \multicolumn{7}{|l|}{ Number of enterprises } \\
\hline Number (mln) & 18.8 & 1.3 & 0.2 & 20.4 & 0.0 & 20.4 \\
\hline$\%$ & $92.1 \%$ & $6.6 \%$ & $1.1 \%$ & $99.8 \%$ & $0.2 \%$ & $100.0 \%$ \\
\hline \multicolumn{7}{|l|}{ Employment } \\
\hline Number (mln) & 37.5 & 26.7 & 22.6 & 86.8 & 43.8 & 130.6 \\
\hline$\%$ & $28.7 \%$ & $20.4 \%$ & $17.3 \%$ & $66.5 \%$ & $33.5 \%$ & $100.0 \%$ \\
\hline \multicolumn{7}{|c|}{ Value added at factor costs } \\
\hline Euros $(1,000 \mathrm{mln})$ & $1,242.7$ & $1,076.4$ & $1,076.3$ & $3,395.4$ & $2,495.9$ & $5,891.3$ \\
\hline$\%$ & $21.1 \%$ & $18.3 \%$ & $18.3 \%$ & $57.6 \%$ & $42.4 \%$ & $100.0 \%$ \\
\hline
\end{tabular}

Source: Authors' elaboration on Eurostat, National Statistical Offices, 2012, DIW, London Economics. 


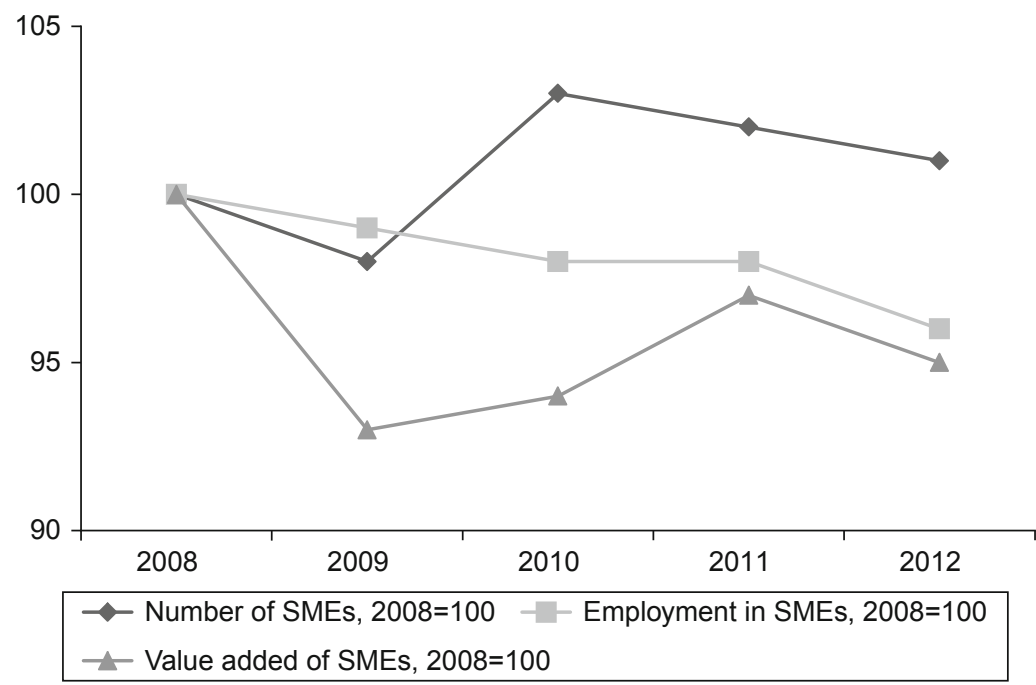

Chart 1.1 Number of SMEs, employment and value added change, EU-27 Source: Authors' elaboration on Eurostat, National Statistical Offices, 2012, DIW, London Economics.

The SMEs system is obviously fundamental also in the production of wealth. The sector generated 57.6 per cent of the gross added value produced by the non-financial private economy in Europe in 2012, for a total of over $€ 3.4$ trillion at current prices against a total added value produced by the non-financial private sector amounting to around $€ 5.9$ trillion. With this regard, microenterprises contributed to the figure by creating a value in the excess of $€ 1.2$ trillion, which translates into 21.1 per cent of the whole production in Europe.

Examining the same aggregates in the period 2008-2012 but focusing only on the SMEs (Chart 1.1), we can observe that:

- As for the number of enterprises, the trend showed a discontinuous performance in the period, reaching its lowest point in 2009, followed by a good recovery in 2010 and a further decline in 2011 and 2012, although at slightly higher levels than in 2008.

- The number of employees followed a downward trend, albeit at very low rates.

- In terms of added value, compared to the 2008 value, there was a reduction of about 10 percentage points in 2009 and a recovery in the 


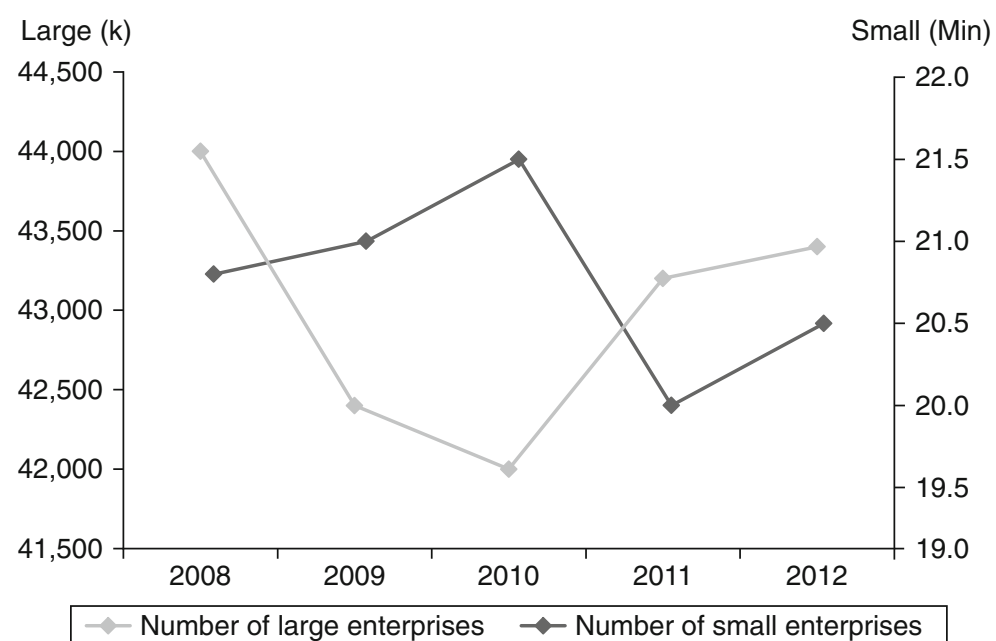

Chart 1.2 Number of enterprises, EU-27, 2008-2012

Source: Authors' elaboration on Eurostat, National Statistical Offices, 2012, DIW, London Economics.

following years, with the 2012 value standing at 95 per cent of the initial value at the beginning of the period.

In strictly demographic terms instead and making a broader comparison (Chart 1.2), the European SMEs followed a different trend than large companies. In 2009, the number of the latter dropped from almost 44,000 to approximately 42,400 and started to recover only from 2011, without reaching the pre-2009 level in 2012. On the other hand, the number of small and medium-sized enterprises grew by 1 million between 2008 and 2010, with a significant drop in 2011 and a good recovery in 2012, when it reached values very close to - albeit lower than - the 2008 figure.

Within the different segments of SMEs according to their size (see Chart 1.3), the dynamics showed considerable differences, influenced by the prevailing trend of microenterprises, which inevitably impacts the whole system.

With regard to the microenterprises, we can observe than only 2010 showed a growing trend, with a growth rate of almost 6 per cent, while the other years recorded drops of 2 per cent a year. This trend reflects the rapid market entry and exit rates typical of this particular segment, which was clearly augmented by the economic and financial crisis. 


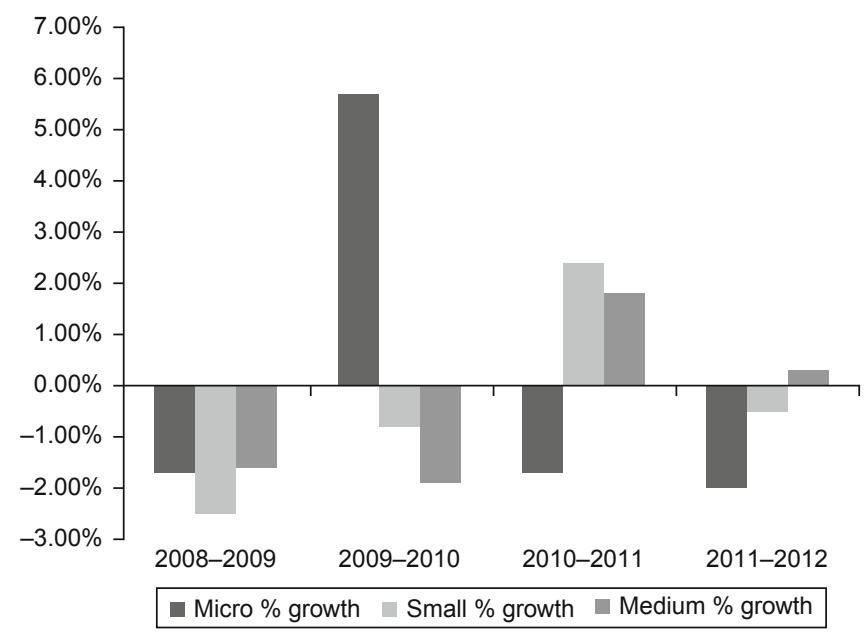

Chart 1.3 Number of SMEs, year-on-year percentage change, EU-27, 2008-2012 Source: Authors' elaboration on Eurostat, National Statistical Offices, DIW, London Economics, 2008-2012.

\subsection{Typical financial profiles, in particular with regard to microenterprises}

As we have just observed, it is not an easy task to determine the characteristics of the SMEs, as they do not constitute a uniform and homogeneous group, varying instead in size, business models, ownership structure, organisational complexity and propensity to growth and innovation.

The presence of multiple characteristics is reflected in the formation of different financial behaviours and approaches to finance showing different degrees of structuring (Chittenden et al., 1996; Reid, 1996; Hall et al., 2004). In other words, the higher the degree of complexity of the companies, ${ }^{9}$ the higher their degree of financial sophistication, which in terms of relationship with the banks and the financial system, gives rise to a whole range of situations and instruments, from ordinary and standardised relationships to contexts characterised by high degrees of customisation and uniqueness (Guelpa, 2005). Hence, it is clear that SMEs cannot be regarded as a macroaggregate to be examined as a whole in an undifferentiated way. The system, in fact, is made of at least two different archetypes, simple firms and complex enterprises, which while having some points in common, show different financial needs and 
requirements and therefore approach the financial system with different kinds of requests for support.

Microenterprises fall in the first category and feature some peculiar operational characteristics that impact also their financial management. Besides the typical operational risk of new ventures, small businesses with growth targets are generally exposed to high financial risks due to scarce availability of own resources. The need to resort to external financing sources exposes them, in fact, to the risks of fund rationing or high and unsustainable borrowing costs. Such risks are particularly relevant when loans are granted to small or new enterprises whose products or services are highly dependent on the application of scientific or technology know-how and characterised by high expected returns matched by equally high level of risk (Storey, 1994). ${ }^{10}$

Financial risks borne by new and small firms originate from some imperfections in the capital markets, which the reference literature ascribes to fiscal burdens and information-related factors, banking and transaction costs and, more generally, the inadequacy of the structure of some financial systems to support the activity of the SMEs and their most innovative projects (Beck et al., 2006). In particular, situations of information asymmetries, due to imperfect knowledge of the business projects by the lenders, may result in particularly severe financial constraints. ${ }^{11}$ This is aggravated by the poor development of the main areas of the business management inside such companies (administration, finance, marketing), resulting in an objective difficulty to provide the lenders with sufficiently clear and articulated information on the company's projects (Devereux and Schiantarelli, 1989; Beck et al., 2005b); a further critical issue is represented by the overlapping of management and ownership, often giving birth to opaque economic and financial situations of both, which prompts lenders to put a greater emphasis on the collateral requirements of entrepreneurs-owners than on the earning prospects of the businesses (Atanasova and Wilson, 2004).

A structurally weak financial profile, poorly equipped to support important development projects, inevitably affects the research of funds and forms of financing, a common issue shared also by other types of SMEs. With this regard, a number of general considerations applicable to the whole category can be outlined. Firstly, the SMEs generally show a limited capacity to fund their projects with their own capital and, conversely, manifest a preference for borrowing, with an inevitable impact on their debt ratio and the level of risk of their business investments, which clearly does not contribute to strengthen their position towards banks and lenders (Pissarides, 1999; Becchetti and Trovato, 2002). While this aspect of their financial structure is driven by correct 
economic motivations, as borrowing is cheaper than using their own capital, also due to the tax deductibility of financial expenses, it is also justified by an element connected with the attitude of entrepreneurs, namely their reluctance to open their capitals to third parties, which could limit their capacity to control and manage the companies. A second peculiarity is represented by the prevalence, among debts, for short-term loans. Here, given the higher costs of this kind of borrowing, this choice appears to be the result of a lack of planning and limited financial knowledge, which both constitute a relevant obstacle to the use of alternative instruments to the traditional forms of financing.

The above-described characteristics are consistent with the indications of the so-called Pecking Order Theory, a financial theory that defines a hierarchy of forms of financing chosen by companies (financial hierarchy), assuming the existence of an order of preferences (Myers, 1984; Myers and Majluf, 1984; Fazzari et al., 1988), where the first choice is represented by self-financing, regarded in its broadest definition and including also personal funds, followed by bank debt and direct issuance of shares. This traditional hierarchy of preferences, though, may be subject to changes according to a number of factors, such as the size, longevity and characteristics of businesses. This leads to the introduction of another proposition, the so-called theory of the Financial Growth Cycle (Berger and Udell, 1998), which relates the types of investors and methods of financing to the aforementioned elements, assuming the existence of a causal link between the use of different financial instruments and contracts and the role of the various institutional financiers/ investors in the funding of companies on one side and, on the other one, the observation of their financial needs throughout the various phases of their development.

The transition from a financial structure characterised solely by selffinancing to another one that includes also other forms of financing constitutes, in another respect, a relevant organisational change, which involves managing increasingly complex situations according to the kind of financing sources used. The reasons are essentially threefold: first of all, companies take on the challenge of interacting with different financial subjects whose interests and objectives are different from their own, therefore enterprises need to engage in a conduct able to match such plurality of targets as much as possible. In addition, the information flows they need to produce are larger and more detailed, resulting in increased burdens for their administration offices or "forcing" them to undesirable disclosure levels. Finally, more market-oriented forms of financing require governance forms of greater complexity and, in any 
case, a number of costs to improve and adjust the firms' organisational structure. In addition, a further distinctive feature shared with other SMEs, especially micro- and small-sized enterprises, is represented by the considerable difficulties in gaining access to financial markets and venture capitals; this inability may result in financial and equity imbalances, such as higher debt levels, lower capitalisation and unbalanced financial statements. Such problems are common in all EU member countries, with different degrees of intensity (Cressy and Olofsson, 1997; Carpenter et al., 2002; Wagenvoort, 2003a; Hutchinson et al., 2006; Ferrando et al., 2007).

Summarising the above considerations, we can observe that the SMEs' financial profile is strongly characterised by short-term bank borrowing, limited use of debt instruments in the market, preponderance of trade payables and limited use of own resources and capital for investments. Banks have traditionally played a fundamental role in the functioning of the SMEs' and microenterprises' financial circuits (Berger et al., 2001; Wagenvoort, 2003b; Avery and Samolyk, 2004; Landi and Rigon, 2006; de la Torre et al., 2008; Beck et al., 2008), providing short-term loans that, de facto, become a long-term form of financing following the periodic renewal of the credit lines granted. The use of bank borrowing, as already pointed out, is due to the poor transparency of information provided by the SMEs, which often prevents lenders from understanding the actual creditworthiness of enterprises applying for loans and limits the number of available funding sources, thus reducing also the options for arbitrage, unlike what happens for larger and more transparent companies, which can easily fund their projects through the issuance of information-sensitive securities, such as shares, or by resorting to the capital markets.

In particular, local banks have always played a prominent role in financing the SMEs, as they - thanks to their operations in geographically circumscribed areas and effective distribution networks - were able to build solid long-term relationship with local enterprises based on reciprocal trust and following a relationship banking pattern (Cole et al., 2004; Berger and Udell, 2002; Prager and Wolken, 2008). Their operating model enjoys a number of consolidated advantages; specifically, the same geographical and cultural vicinity as the enterprises; good customer relationship management; the acquisition of information on the local environment and clientele, which becomes an information edge when assessing creditworthiness and credit lines; the search and use of soft information, namely quality and reserved data, a type of non-structured information which can only originate from 
long-term relationships with the borrowers; a light and efficient organisational structure, which facilitates their capacity to pick up information and take decisions in a timely effective fashion. The lending activity, which represents the core business of such banks, is thus strengthened by virtue of a direct and privileged knowledge of the borrowers and the possibility of a sort of social agreement and checks that go beyond the terms of formal contracts (Petersen and Rajan, 1994; Cole and Rebel, 1998; Scott, 2004; Berger et al., 2004).

While the above-illustrated characteristics are applicable to the whole category of SMEs, when the focus is put on microenterprises instead, the following peculiarities can be observed:

- Net profit levels are quite low; this limits their capacity to fund their own investments and projects by using internal resources and capital; conversely, they are most likely to resort to bank borrowing, an option driven also by their financial structure, which is weaker than other types of companies.

- Discontinuous ability to raise capital, which shows periods of relatively high investments and others when no investments at all are made.

- Debt mainly originates from bank borrowing, although it must be stressed that several microenterprises have no relationships at all with the banking system.

- The amount of funding provided directly by their members is more significant, as they tend to offset the risks of high indebtedness levels and confer greater stability to their financial structure.

- Relationship with banks is restricted to a limited number of intermediaries.

In short, all this leads to the frequent use of self-financing methods, with all the relevant limits, and the general absence of any kind of reserves, even minimal, to cope with any situation of instability that may arise from general economic issues (economic cycles, crisis in the sector), business problems (loss or failure of some key customers), extraeconomic matters (theft and breakdown of equipment and machinery) and personal occurrences (from incidents on business trips to various unforeseen circumstances).

A recent analysis carried out by the Bank of Italy (De Mitri et al., 2013) in the country, which, among the EU members, is the nation where enterprises with ten or fewer employees have the greatest relevance in terms of turnover and employment, confirms these aspects and shows that the indebtedness levels of microenterprises, calculated through the 
ratio of financial debt to its sum with equity, is always higher than within other types of companies. This is due to the fact that many of them do not borrow from banks (around 40 per cent) because they are unable to obtain external credit lines due to their young or opaque structure. The study highlights also how microenterprises, unlike other types of companies, are also frequently reliant on funds provided by their own members. With regard to their relationship with the banks, which is limited to a few lenders, microenterprises are burdened by the more stringent collateral requirements and application of higher interest rates. Microenterprises generally manifest different kinds of financial needs according to the various phases of their life cycle: whereas, in fact, during the start-up phase they need to make sure to have an adequate share capital, avoiding the creation of undercapitalised enterprises, which could turn into a "chronic" issue and jeopardise the balance of future financial flows, in the survival phase instead, which is common to all microenterprises, they need to be able to cope with unexpected events that may severely impact their business due to an insufficiency of financial reserves. Moreover, if we consider the growth stage, financing is required both for investment purposes and the necessary and automatic increase of their working capital.

Generally, access to credit and finance ultimately represents a critical issue for all microenterprises about to start and develop their business. With this regard, an important set of measures adopted at European level, aimed at solving a number of issues, including the credit difficulties, characterised by the relevance of its scope and institutional participation, is contained in the Small Business Act for Europe (SBA), which proposes, within a global strategic agreement for all the European Union and its member countries, a series of interventions revolving around ten key principles and aimed at providing long-term support to the development of this kind of enterprises. ${ }^{12}$

In addition, the European Commission kicked off a series of programmes that involve the allocation of funds and the development and diffusion of instruments more suitable to meet the requirements and needs of the SMEs, such as intermediate financing, collaterals and microcredit. In particular, microfinance was introduced into the development arena slightly more than two decades ago. However, the widespread adoption of the microfinance model did not occur until the early 1990s. Since the mid-1990s, microfinance programmes and institutions have become an increasingly important component within the strategies to promote micro- and small-enterprise development and especially to reduce poverty (Mosley and Hulme, 1998; Morduch, 1999; Hartaska, 2005; Green et al., 2006; La Torre and Vento, 2006; Erikkson et al., 2011; 
EIF, 2012). In this perspective, the European Commission (see §§1.7ff.) consistently increased the amount of financial resources to be allocated to microcredit programmes, both through direct contributions and funds granted to the various national funds.

The projects financed through European funds must be constantly monitored in order to observe their efficacy, though - namely, whether the proposals laid out are actually implemented through the tools provided and also what kind of critical issues can be observed during the application phase. ${ }^{13}$

\subsection{The supply of credit in the years of crisis}

One of the main characteristics of the recent crisis gripping Europe has been the decline in credit granted to businesses, with different degrees of seriousness according to the single country situations. This phenomenon, known as credit crunch, affected the SMEs' capacity to raise the financial resources needed (Canton et al., 2010; Buca and Vermeulen, 2012; Buera et al., 2012; Iyer et al., 2013; Klein, 2014). The evidence commonly found in literature, in fact, agrees in indicating that the smaller enterprises - those with a lower turnover and a relatively young credit history that are most likely to resort to internal funds and operate with lower capital - were those mostly affected by the credit crunch, as they faced increasingly stringent credit constraints during the years of the financial crisis in Europe and their financial situation inevitably deteriorated (Castelli and Modina, 2010; Ferrando and Griesshaber, 2011; Dallago and Guglielmetti, 2012; Varum and Rocha, 2013). The difficulty to access credit affects not just the ordinary operations of smaller enterprises but also their capacity to grow, turning liquidity issues into permanent and chronic weaknesses. The causes of such an occurrence are partly structural and related also to the specific characteristics of the SMEs themselves, as we have seen in the previous sections, in particular to the information asymmetries that arise when dealing with them. Banks regard these enterprises as "less transparent"; as their business capacity is not easy to be assessed, their balance sheets do not offer comprehensive information and their credit history is not as long as that of larger companies. To this must be added greater fixed costs to be borne by the lenders for external assessment and monitoring activity, both before and after the provision of credit.

For these reasons, the suspicious attitude of the banks is partly justified, as - especially in times of economic recession - they generally tend to adopt cautious behaviour in the provision of credit in order to preserve the quality of their balance sheets and assets. As a result, SMEs are more prone to be 


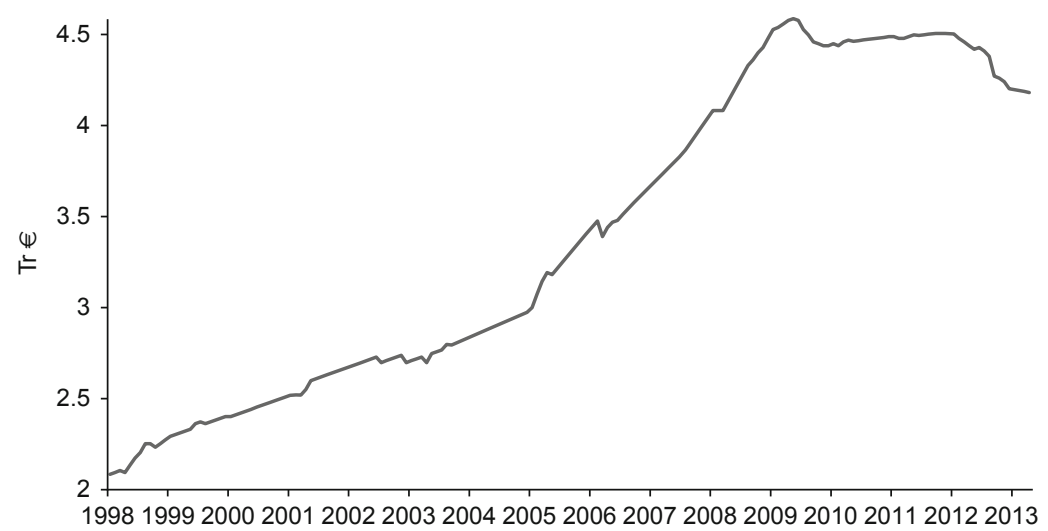

Chart 1.4 Outstanding loans to non-financial corporations in the euro area Source: Authors' elaboration on ECB Data (2013).

affected by risk-averse banks than larger companies, since they are generally perceived as more likely to default than other companies.

Bank lending to non-financial corporations in Europe showed a constantly growing trend in Europe during the period 1998-2008 (Chart 1.4), rising progressively from $€ 2.1$ trillion at the beginning of the decade up to a peak of $€ 4.7$ trillion towards the end of 2008 . The trend reversed in 2009, with a gradual decrease in the volume of loans in the following years, which - compared to the peak - fell by 9 per cent, down to €4.2 trillion, in October 2013.

In recent years the issue of access to credit has become increasingly relevant in Europe; this is confirmed also by the research and numerous studies constantly issued by interested institutions; all highlight the most significant effects of the problem, both with regard to the business point of view and its financial aspects, showing the intensity of these change over time and their effects on the different types of businesses (micro, small, medium, large enterprises) and, occasionally, also for the single countries. Our research will propose empirical evidence of some elements deemed of particularly interest in order to get an understanding of the SMEs' financial situation in the current context, drawing from contributions prepared by different European institutions and bodies and referring to them for more detailed analysis and in-depth consideration on other relevant topics.

To evaluate the access to credit for the European small and mediumsized enterprises in the same period, first of all we can take a look at the performance of the SMAF (SMEs' Access to Finance) Index, a parameter 
proposed by the European Community to monitor the developments in the sector and analyse differences in each member country. This indicator, calculated by using the EU 2007 data $=100^{14}$ as a reference parameter so as to allow comparing both the results of different countries and the overall results over a period of time, is constructed as a weighted average of two subindices: the index of access to financial debt, which accounts for 85 per cent, and the index of access to capital funding, which accounts for 15 per cent. ${ }^{15}$ We observe that the SMAF value significantly increased from 2008 to 2010 and then stabilised at slightly lower values in the following two years (Chart 1.5).

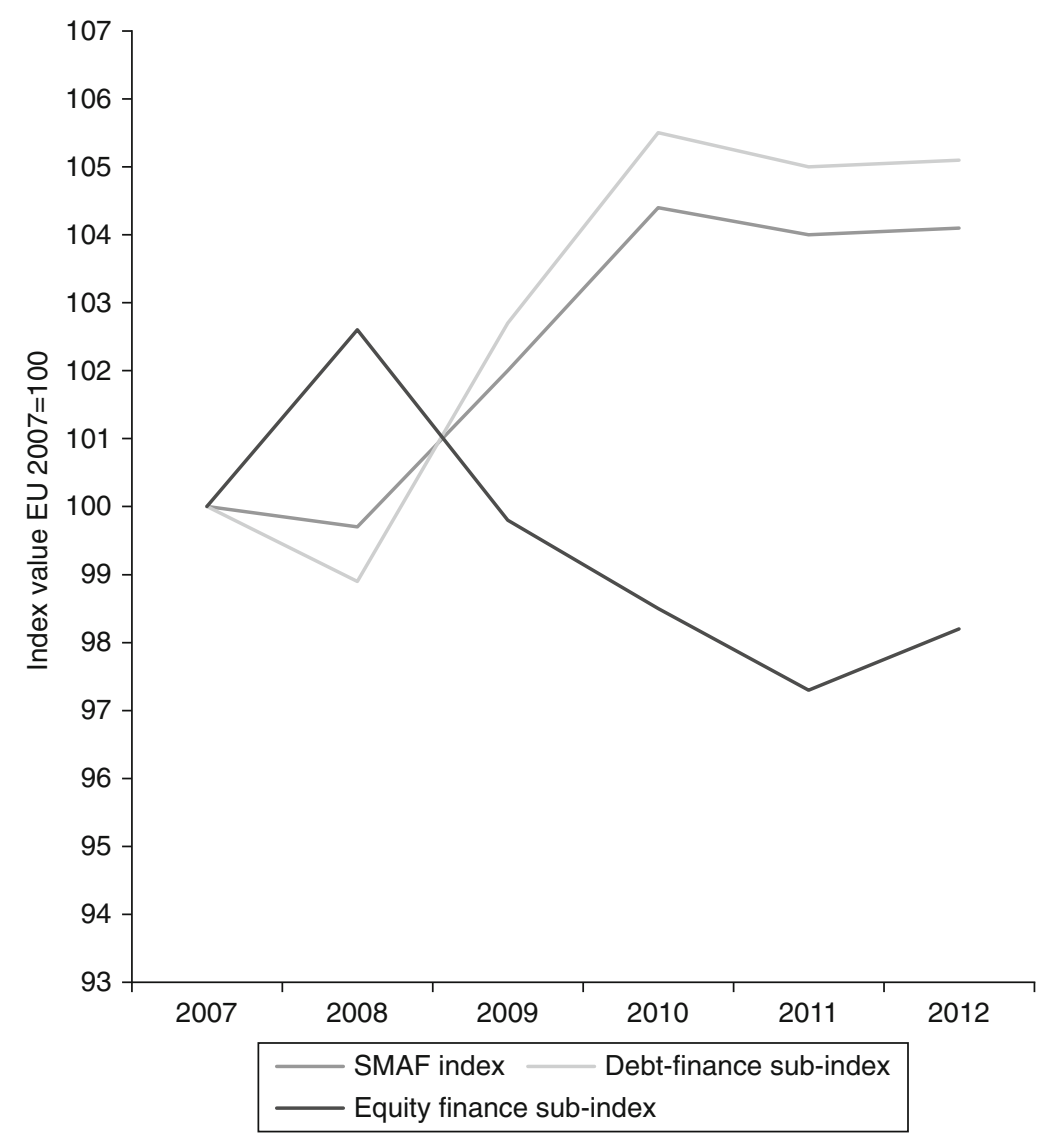

Chart 1.5 SME access to finance (SMAF), index and its sub-indices for the EU Source: Authors' elaboration on European Commission (2013). 
The trend reflects the performance of the subindex financial debt, which had a similar pattern, also due to the decrease of interest rates on loans and overdrafts recorded from 2008 onwards. Investments in venture capital by private equity operators instead significantly dropped between 2008 and 2011, then slightly picked up in 2012. In this context, it is interesting to observe through which technical forms enterprises receive financial support from the banking system. Chart 1.6 indicates how the forms of financing vary greatly according to the size of the businesses. Microenterprises show a preference for using financing sources in the likes of bank overdrafts, credit line overdrafts and credit card overdrafts, while forms such as trade credits and bank loans are used to a lesser extent; even lower is the use of instruments such as leasing, hire purchase and factoring, which are, conversely, more popular among large companies.

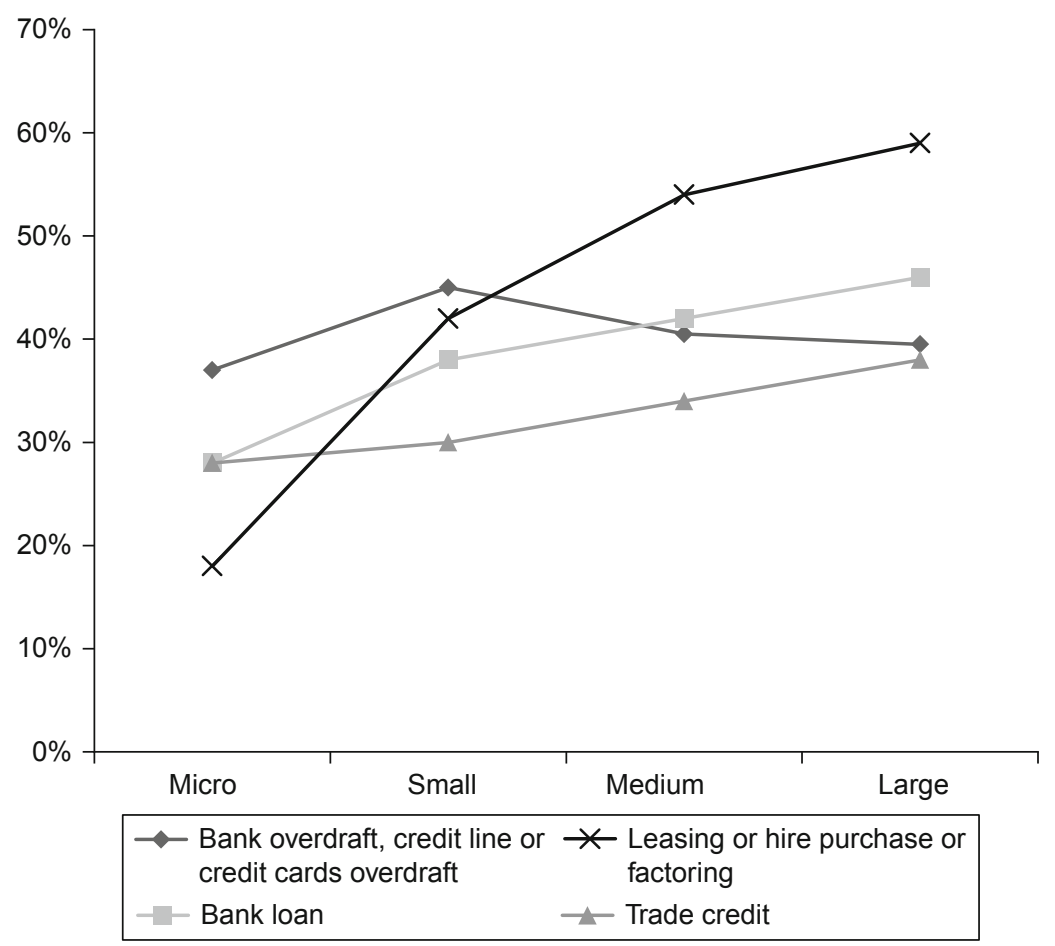

Chart 1.6 Enterprises having used different financing sources (by enterprise size class, April to September 2013)

Source: Authors' elaboration on ECB data (2013). 
This highlights that with the exception of the first type of instruments, the use of other financing sources increases as the size of enterprises grows. These numbers reflect the difficulties to access credit by microenterprises, which, given their inability to enjoy more stable funding sources in a systematic way, in situations of liquidity crisis are more bound to rely on instruments that are less risky for the banks, as they involve smaller amounts, but are characterised by higher costs when the relationship is prolonged over time. Moreover, trade credit, leasing and factoring are strictly connected to business activities of the companies, and their function of reserve (buffer) during recessions could be limited by a reduction in the trade of goods and services.

Taking a look at the elements that determine the financial structure of enterprises, we can observe that with regard to SMEs, during the years of the crisis, profits, interventions on equity and the relationships with the banks all recorded lower values than those of large companies. As indicated by Chart 1.7, from 2008 onwards, the SMEs, although with an irregular trend, saw a drastic reduction of their profits, which fell

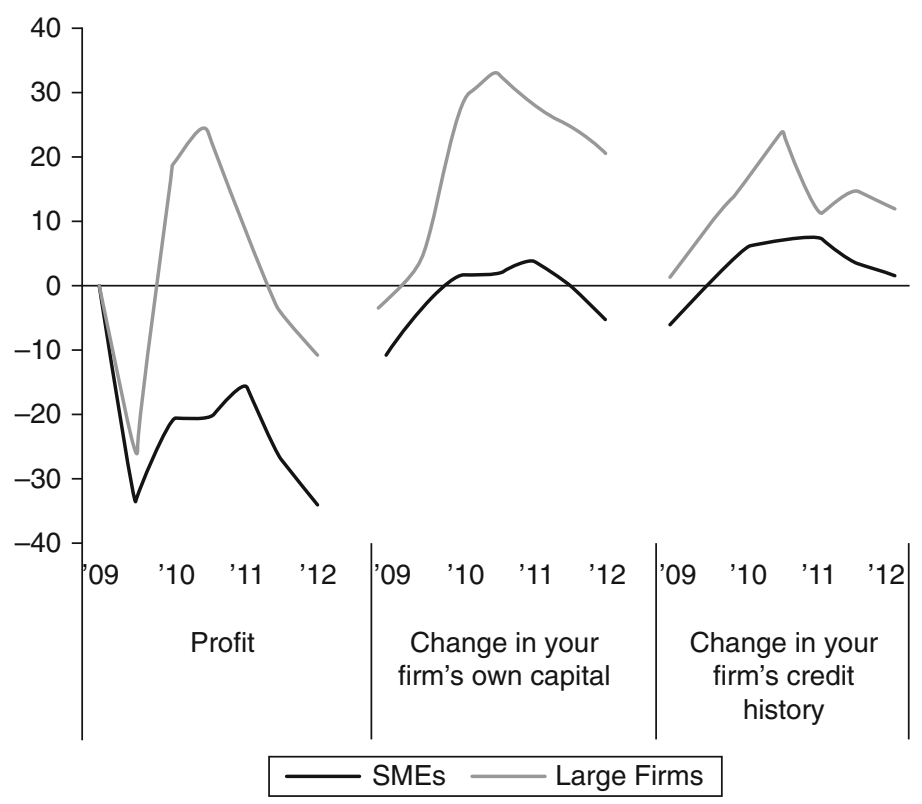

Chart 1.7 Financial health of euro area SMEs compared with large firms Source: Authors' elaboration on ECB Statistical Data Warehouse (2013). 
by approximately 35 percentage points during the period 2009-2012, a decline greater than the one of large companies, whose profits showed a fluctuating trend and were reduced by around 10 per cent if comparing the end-of-period figures and the 2009 value.

Even in terms of variations in equity, the SMEs' performance is quite different, with a gap of approximately 25 percentage points compared to large companies, which were able to improve the quality of their balance sheets. The same pattern can be observed with regard to the SMEs' credit history with the banking system.

The credit crunch of the last two years has greatly affected most SMEs, which, given their limited size in terms of turnover and geographical range of operations, are often unable to rely on funding sources other than the traditional banking system. Access to financial markets, typical of the equity and bond markets, would instead allow these enterprises to acquire the necessary capital to fund investment plans for their development and growth in an alternative way. From this point of view, it appears clear the gap in terms of perceived needs for external funding between large companies and other kinds of companies (Chart 1.8), within a general trend that saw an initial phase (until 2011) where all types of companies clearly manifested such a need and a second phase when the demand for credit decreased,

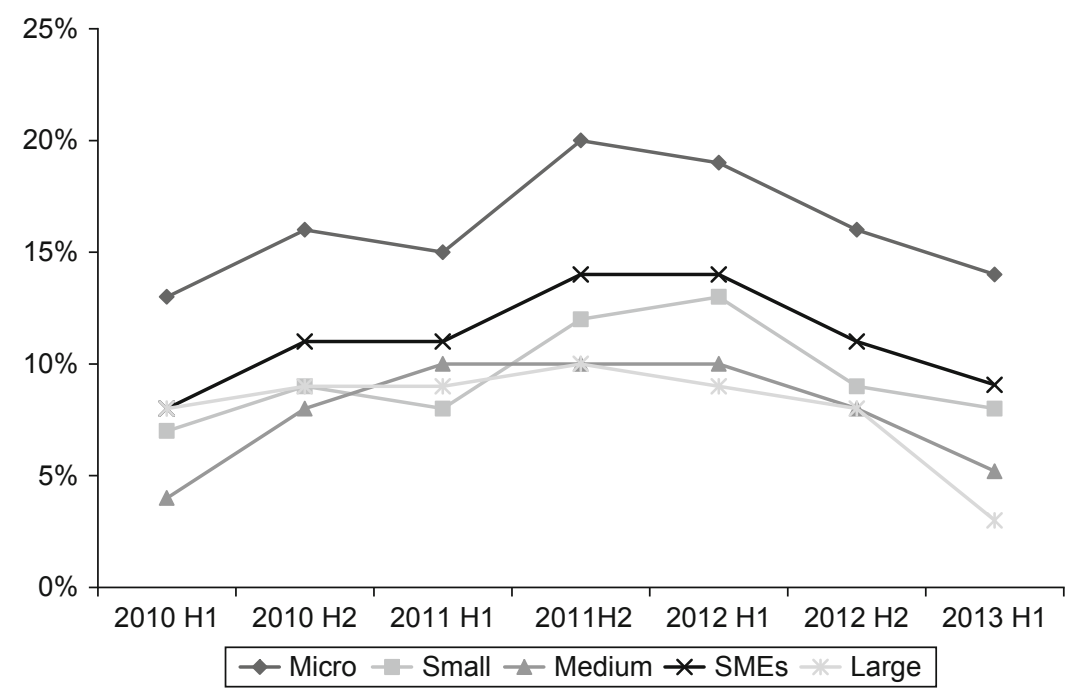

Chart 1.8 Perceived change in the external financing gap (by firm size) Source: Authors' elaboration on ECB Statistical Data Warehouse (2013). 
most likely due to a contraction in investments following the economic crisis.

Of course, it is absolutely normal that microenterprises are those businesses that, more than others, develop a perception to be in need of access to external funding; such need, after a peak reached in 2011, seems to have decreased again from the first half of 2012, with a spread of the SME average that, starting from the second half of 2011, never dropped below 5 percentage points, a further confirmation of their peculiar financial profile. The afore-examined difficulties are also related to the fact that interest rates on loans up to $€ 0.25$ million, which represent the bulk of those granted to small enterprises (so-called small loans), point out values generally higher than those applied to loans between $€ 0.25$ million and $€ 1$ million (so-called medium-sized loans) and to loans greater than $€ 1$ million (so-called large loans; Chart 1.9). More precisely, in the aftermath of the outbreak of the economic crisis, interest rates on loans up to $€ 0.25$ million gradually rose until they reached a 5 per cent peak in 2012.

Starting from 2012, the market has a general decrease of the interest rates: for loans greater than $€ 0.25$ million, the decrease was around 1 per cent in the period 2012-2013, while the interest rate level for loans of less than $€ 0.25$ million showed a fluctuating performance, although in a downward trend for about half a percentage point, that widened the spread in terms of borrowing costs. In particular, if we look at the difference between the interest rates applied to small loans (up to $€ 0.25$ million) and those on large loans (exceeding € 1 million), we can observe that the spread progressively expanded as the crisis prolonged over time, reaching an average of around $250 \mathrm{bp}$ since March 2012. This figure shows, once again, the difficulties met by SMEs in accessing credit compared to large companies. Given their incapacity to provide banks with the same level of information and the economic-financial solidity of large companies, banks see smaller enterprises as more risky and less solvent; therefore, they pay higher costs to access credit. The difference between interest rate levels is therefore the result of a difference in terms of specific business risk associated with the two types of enterprises and can also be explained by the fact that small-sized companies are greatly dependent on the national banking system, also in light of their reduced flexibility in terms of access to credit; on the other hand, large companies generally boast a more consolidated and diversified relationship with the capital market.

An effective source for examining the financial peculiarities of the SMEs are in the periodic surveys carried out at a European level by the Survey on access to finance of small and medium enterprises in the euro area (SAFE). 
(dq) peəлds

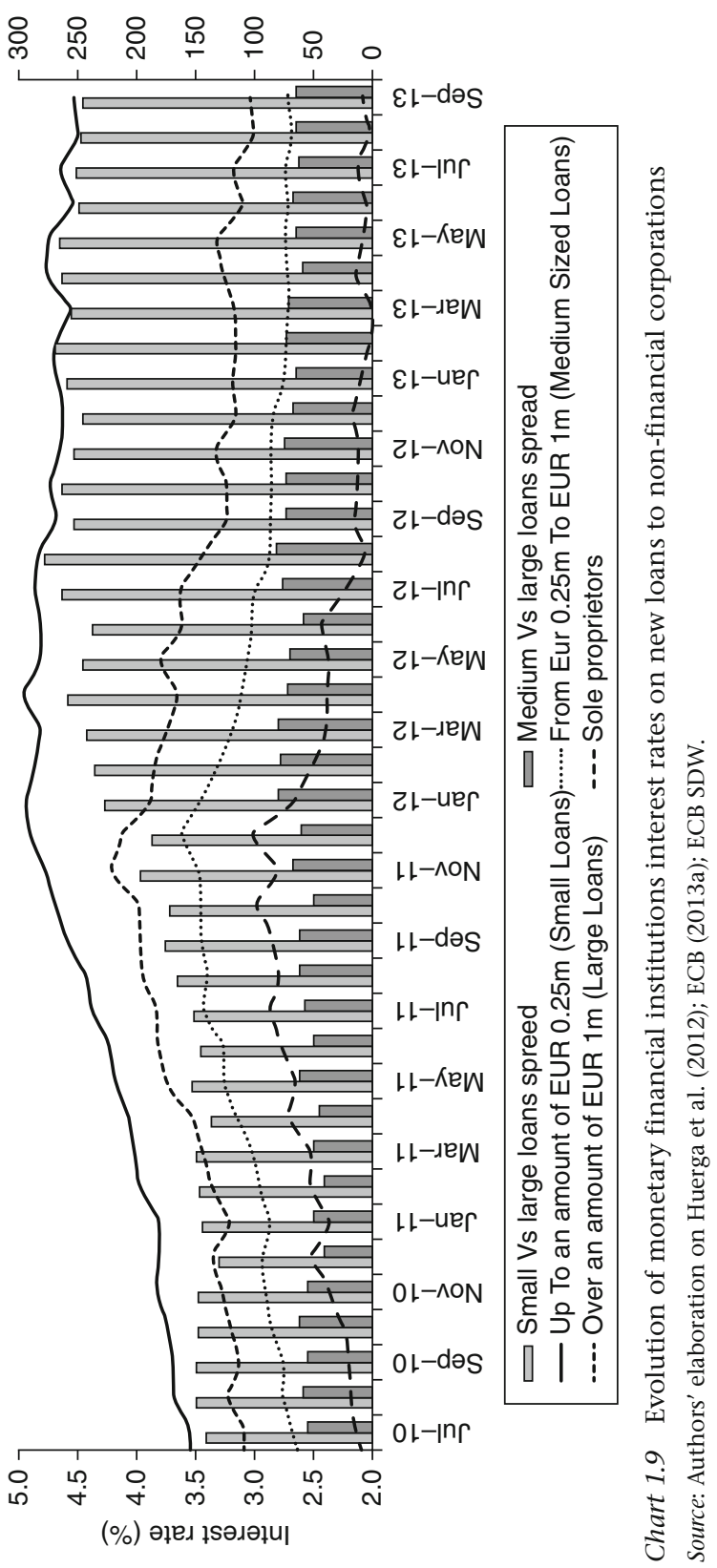




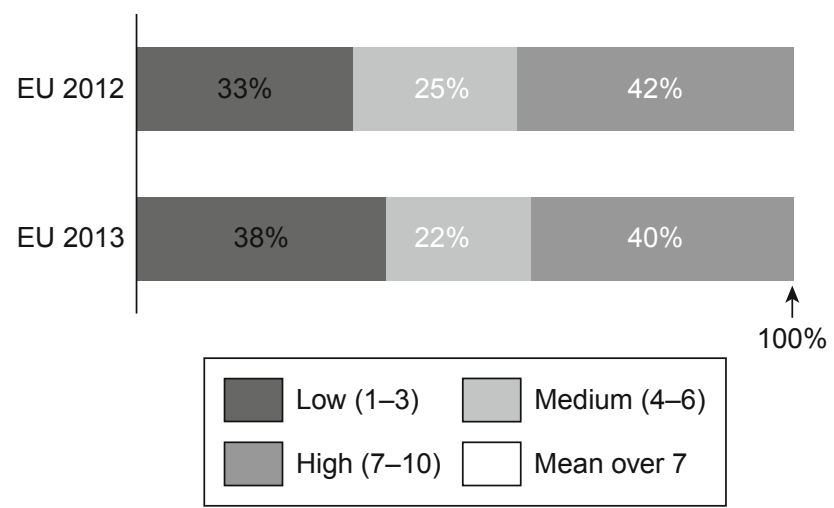

Chart 1.10 Pressingness of access to finance as perceived by SMEs across euro area countries

Source: Authors' elaboration on ЕСB (2014), "Survey on the access to finance of small and medium-sized enterprises in the euro area - October 2013 to March 2014".

According to the results published in the April 2014 survey, ${ }^{16}$ it emerged that access to credit is definitely perceived by SMEs as one of the main critical aspects (14 per cent of the respondents), surpassed only by the need to win new customers ( 22 per cent of the sample examined). ${ }^{17}$ This issue is even more relevant if referred solely to microenterprises, showing higher percentages of consensus than those expressed by the small and medium-sized companies with figures close to 20 per cent in the last three years, a confirmation of the credit hurdles faced by this type of business. ${ }^{18}$

More specifically, when companies were asked how pressing the problem of access to credit was on a scale from 1 to 10 (where 1 corresponds to "not worrying at all" and 10 to "extremely worrying"), the average value recorded was generally above 7 (Chart 1.10), further evidence that, despite some signals of economic recovery in the second half of 2013, the SMEs' perception of a reluctance by banks to fund them remains high.

The SAFE 2014 search highlights also that approximately 4 per cent of European SMEs increased their needs for a bank loan, while 7 per cent of them incremented their need for an overdraft. ${ }^{19}$ Both these figures are slightly lower than in the period Aprilto October 2013, within a picture where, at the end of 2013, 54 per cent of European SMEs declared they resorted exclusively to external financing sources for investments. Narrowing the field to the microenterprises sector, their need for 


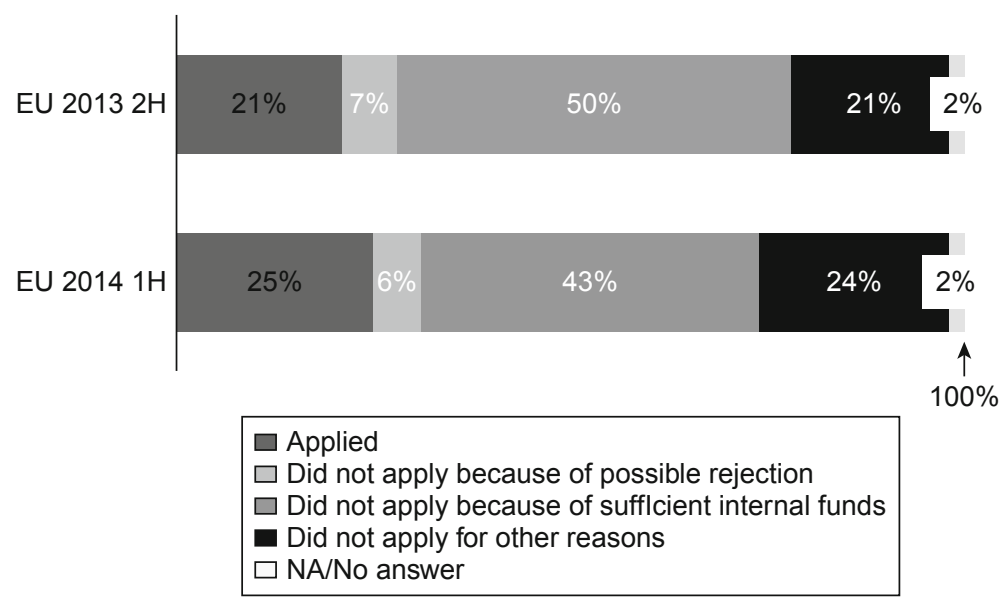

Chart 1.11 Applications for bank loans by SMEs across euro area countries Source: Authors' elaborations based on ECB (2014) "Survey on the access to finance of small and medium-sized enterprises in the euro area - October 2013 to March 2014".

overdrafts increased in the same period by more than 10 per cent, due to a greater difficulty in raising funds through other channels. ${ }^{20}$ The survey also indicates (Chart 1.11) that 25 per cent of the SMEs applied for a loan during the period October-March 2014 against 21 per cent of the previous report, while 43 per cent of them did not apply at all because they used their own internal funds to finance the necessary investments compared to 50 per cent of the previous group sampled, and a further 24 per cent of enterprises did not apply for other reasons. On the other hand, the percentage of companies that did not apply for loans due to fears of rejection fell from 7 to 6 per cent. Finally, as for other aspects of the SMEs-banks relationship, we can observe that:

- Around 66 per cent of enterprises were granted the loans they applied for, while 11 per cent of the applications were rejected and 10 per cent of them only partly approved. ${ }^{21}$

- Compared to the values of the end of 2013, the percentage of companies regarding as relevant the burden of borrowing-related costs, commissions and expenses was slightly lower (from 43 per cent to 40 per cent); likewise, the percentage of companies that pinpointed the interest rate levels as the critical element in their relationships with the banking system dropped (from 19 per cent to 9 per cent; Chart 1.12). 


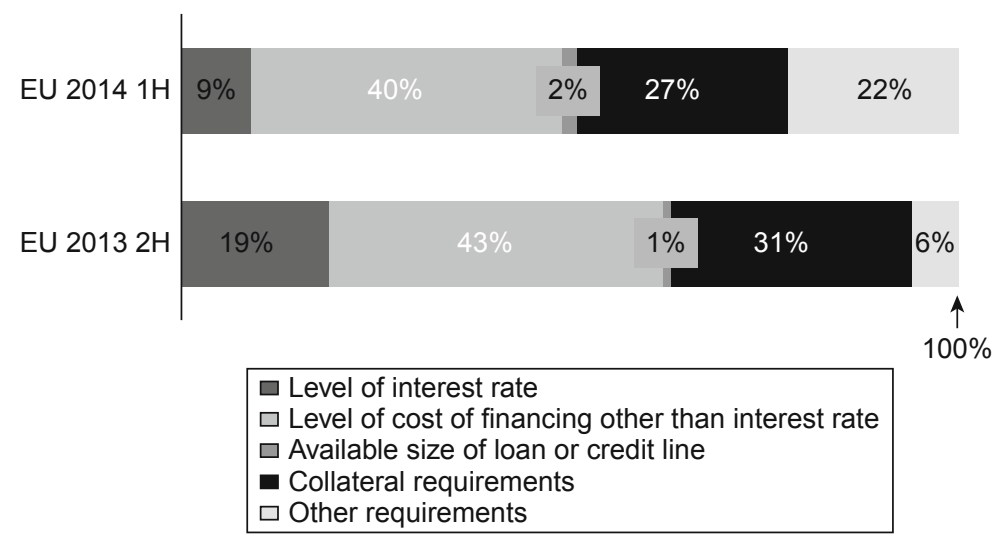

Chart 1.12 Change in terms and conditions of bank loans granted to euro area SMEs

Source: Authors' elaboration on ECB (2014) "Survey on the access to finance of small and medium-sized enterprises in the euro area - October 2013 to March 2014".

- Always comparing the percentages of the beginning of 2014 with those of the previous survey (Chart 1.12), the study recorded a reduction in the importance attributed to collateral requirements, which was indicated by 27 per cent of the interviewees at the beginning of 2014 against 31 per cent of the previous half.

Overall, qualitative analysis, too, highlights that generally all SMEs faced, and still face, problems and difficulties in accessing credit, although a number of parameters contained in the first survey carried out in 2014 have shown a slight improvement.

One more point deserves to be stressed. When the focus shifts from the use of bank loans to other financing sources, either in the form of debt or equity, the picture shows that SMEs have very limited opportunities; a few funding instruments appear basically foreclosed to them. Whereas the use of bank loans is widespread and properly known, as well as the choice for self-financing, namely the reinvestments of profits in the business or the sale of non-strategic assets or assets deemed not directly functional to the core business, alternative and more sophisticated forms of financing such as the entry of new investors in the companies' equity, the issuance of debt securities, subordinated loans, participation loans or similar are mostly unknown or unfeasible. Chart 1.13 clearly highlights this situation. 


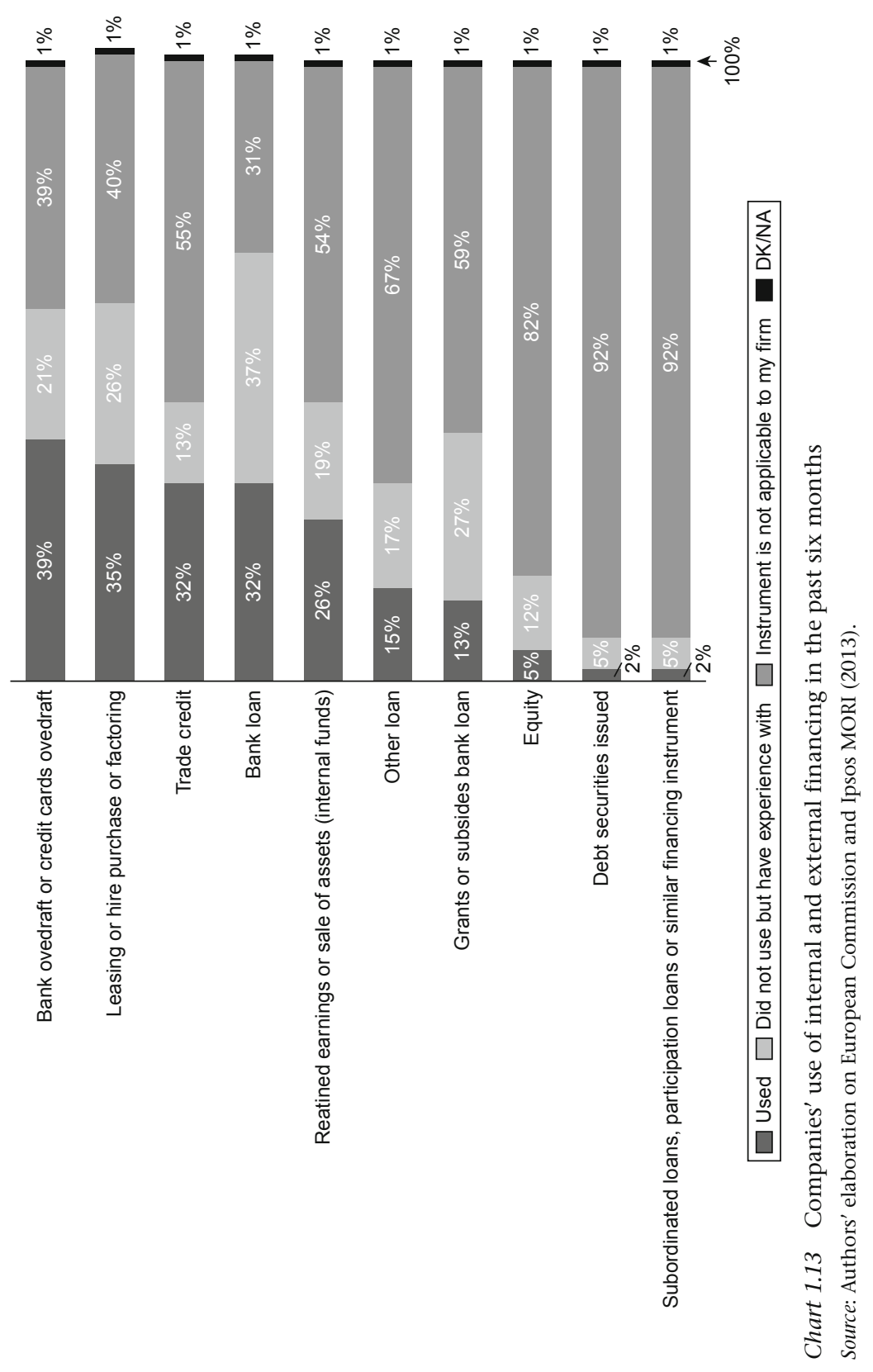


Of course, a number of financial instruments can be applied only to some types of SMEs - or rather those characterised by high performance and results, those that operate in particularly lucrative sectors or business areas showing great potential for growth, those boasting a strong propensity for development and internationalisation and those led by entrepreneurs who already improved their management quality and structure. On the other hand, we should consider that almost all companies started small before growing and reaching their definitive size, following a standardised model of development where each phase is marked, from a financial standpoint, by specific measures, needs and requirements.

\subsection{Some summary considerations on data examined}

The foregoing considerations and data examined show the general fragility and precariousness of the SMEs' financial profile and that of microenterprises in particular, with a strong dependence on bank borrowing on one side and a widespread difficulty accessing credit on the other. This aspect makes them particularly vulnerable or exposed to the risk of exit from their own market as it affects, in most cases, their capacity to start development and growth processes.

Consequently, in light of their specific weight within the European economy in terms of number as well as their relevant contribution to the production of wealth and employment, it is absolutely mandatory to create and strengthen the conditions to facilitate their access to credit and, generally, to additional financing sources.

The primary obvious and natural recipient of such recommendations is the banking system, which besides traditional lending activity in all its technical forms, should extend to the SMEs the provision of alternative instruments and opportunities to raise capital by promoting innovative tools and solutions, in the form of both debt and equity, including also studies on their feasibility and adapting their form to the needs and requirements of the enterprises, following an approach where the advisory part and the supply of products/services are combined in accordance with a problem-solving approach. While the SMEs could seem excluded from such instruments due to their peculiar requirements and poor transparency, their absolute relevance within the European economy is a good enough reason to prompt banks to include them in their commercial and strategic plans, starting from the smaller companies that present characteristics of excellence. SMEs led by innovative and competent entrepreneurs and with a strong propensity to grow are 
the ones most in need of innovative and structured financial services, as they are also the ones most likely to undergo processes of restructuring, concentration and internationalisation.

On the other hand, an additional effective support to microenterprises - which, again, represent the most widespread type of enterprises in Europe - can be provided, together with other structural measures to be implemented by banks within their ordinary lending activity as well as by other institutions involved, by microcredit and microfinance, with the obvious and adequate adjustments in terms of services, products and methods of provision. The growth of the microcredit and microfinance sectors and their systematic application among operators, both by specialised financial intermediaries and enterprises making use of them, represent a clear and explicit target of the European Commission, which has drawn an actual manifesto to shape its development policies in this direction for the years to come. The next section explains the response of the EU Commission to the different kinds of financial need of small business and microenterprises.

\subsection{Access to credit in the European Commission's view}

According to the report partially entitled Access to finance (EC, 2013), ${ }^{22}$ published by the European Commission and the European Central Bank (ECB), access to credit (EC, 2013), ${ }^{23}$ especially for young and small enterprises, remains one of the main concerns debated by the EC. The current economic environment has brought SME needs in particular focus, given the significantly tightened credit supply conditions arising from reduced ability and willingness of banks to provide the financing on which this sector is particularly reliant.

In 2008, the EC and the European Central Bank (ECB) joined forces to collaborate on a survey on access to finance for SMEs in the European Union and established the Survey on the Access to Finance of Small and Medium-Sized Enterprises (SAFE). The study, conducted across 37 countries, including the 28 European Union (EU) member states and 17 euro area countries, was undertaken in June-July 2009, in August-October 2011 and, most recently, in August-October 2013.

In detail, the survey ${ }^{24}$ examines SMEs:

- financial situation, growth (past and future), innovative activities and need for external financing;

- use of internal funds and external sources of financing;

- experiences when applying for different types of external financing; 
- use of loans, size and reasons behind taking out specific types of loans;

- views on the extent to which different types of financing are available to them;

- expectations regarding future loan finance with banks and other sources of funding.

The survey at issue highlighted a worsening in the terms and conditions of bank loan finance in 2013, due to an increase in interest rates and collateral requirements. Approximately one of three of the SMEs examined (EC, 2013) ${ }^{25}$ did not get the whole bank loan finance needed for 2013; amongst the latter, small and young enterprises are more exposed to the risk of obtaining just a part of the loans they applied for or, in the worst cases, no financing at all. Scarcity of collateral and other burdensome conditions required by banks represent the most common obstacles faced by businesses seeking bank loan financing, followed by the excessive burden of interest rates. Particularly weak was also the use of venture capital financing, which involved only 5 per cent of the SMEs (EC, 2013); ${ }^{26}$ generally, it is a scarcely used form of funding and characterised by high costs.

In order to promote access to credit under the 2007-2013 plan, ${ }^{27}$ just ended, the EC activated several instruments: those within the Entrepreneurship and Innovation Programme, such as GIF and SMEG (EC, 2006), ${ }^{28}$ and other innovative instruments in collaboration with the EC and the European Investment Bank and other financial institutions (JEREMIE, JASPER, JESSICA and JASMINE). In the new plan, the European Commission intends to tackle the issue of access to credit through the new programme for competitiveness (COSME, ${ }^{29}$ Programme for the Competitiveness of enterprises and SMEs). Running from 2014 to 2020, this is the first EC programme exclusively dedicated to SMEs.

\subsection{European Investment Bank: mission and operating methods}

The European Investment Bank (EIB) ${ }^{30}$ is the European Union bank; it contributes to the implementation of the EU objectives through investments in projects aimed at promoting integration within the EU, balanced development of countries and economic and social cohesion, as well as the development of an economy based on knowledge and innovation.

The EIB, both a bank and an independent institution within the EU, enjoys its own legal personality, financial autonomy and decision-making 
structure. Its task is to contribute to the balanced and steady development of the common market (EU) by financing, through the granting of loans and collaterals, the following projects on a non-profit basis in all sectors of the economy (EU, 2010): ${ }^{31}$

- projects for developing less-developed regions;

- projects for modernising or converting undertakings or for developing fresh activities called for by the establishment or functioning of the common market, where these projects are of such a size or nature that they cannot be entirely financed by the various means available in the individual member states;

- projects of common interest to several member states which are of such a size or nature that they cannot be entirely financed by the various means available in the individual member states.

In carrying out its activities, the bank facilitates the funding of investment programmes, in conjunction with measures provided by EU structural funds and other financial instruments, by applying interest rates $(\mathrm{EU}, 2010)^{32}$ consistent with prevailing conditions on the capital markets and calculated so as to allow the bank to meet its obligations, cover its costs and risks and create a reserve fund (pursuant to art. 22 of the general EIB Statute; EU, 2010). ${ }^{33}$ Table 1.3 lists amounts of EIB investments $(€)$ made in recent years and divided by different business sectors.

\subsection{What is the EIF?}

The European Investment Fund (EIF) ${ }^{34}$ was established in 1994 as the EU financial entity specialising in supporting SMEs. The EIF is the European Union body dedicated to providing risk-finance integrated development solutions for SMEs in the EU member states, countries included in the European Free Trade Association (EFTA) and EU candidate countries. It offers a variety of financial solutions to public and private intermediaries, with the aim of supporting access to credit for the SMEs as well as correcting a number of market imbalances. The EIF is committed to promoting EU objectives in terms of innovation, regional development, entrepreneurship, growth and employment. Its ownership structure was modified in June 2000; currently, the main EIF shareholder is the European Investment Bank (61.2 per cent), followed by the EC (30 per cent) and 28 public and private financial institutions from EU member countries Turkey and Croatia (EU candidate countries) 


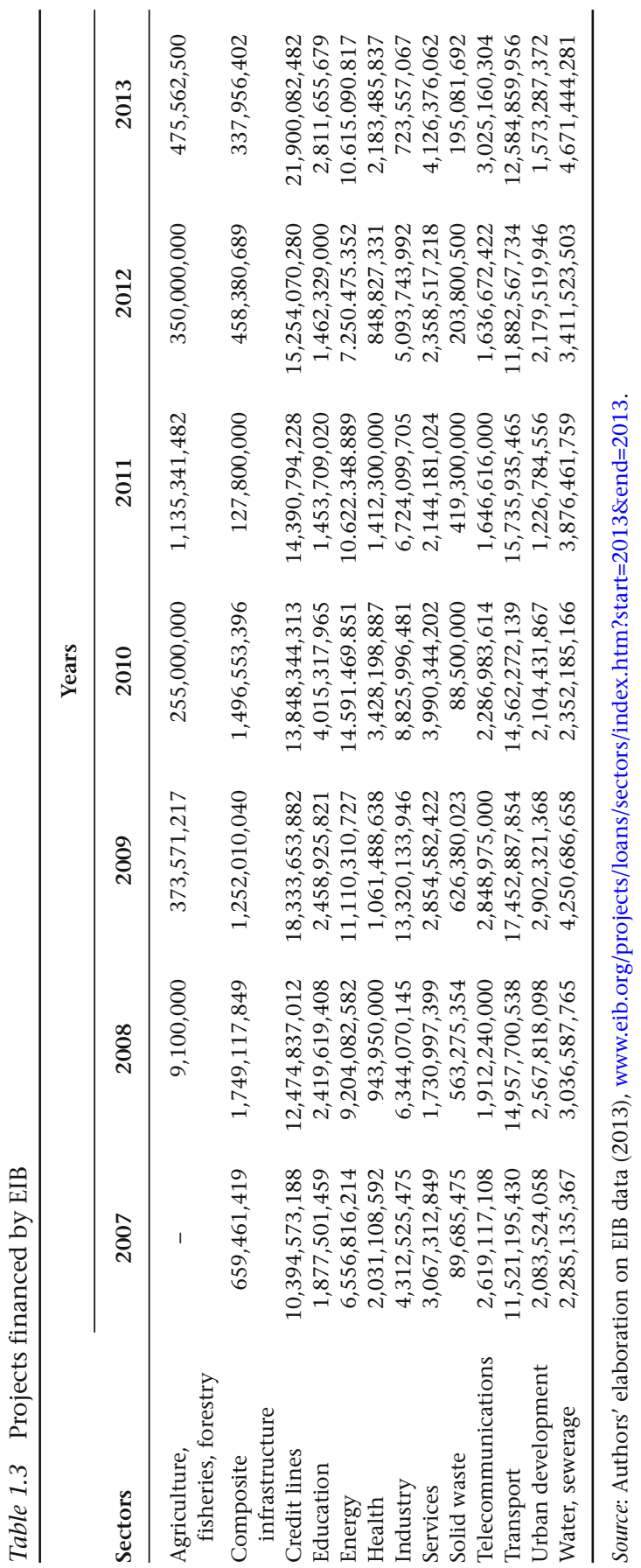




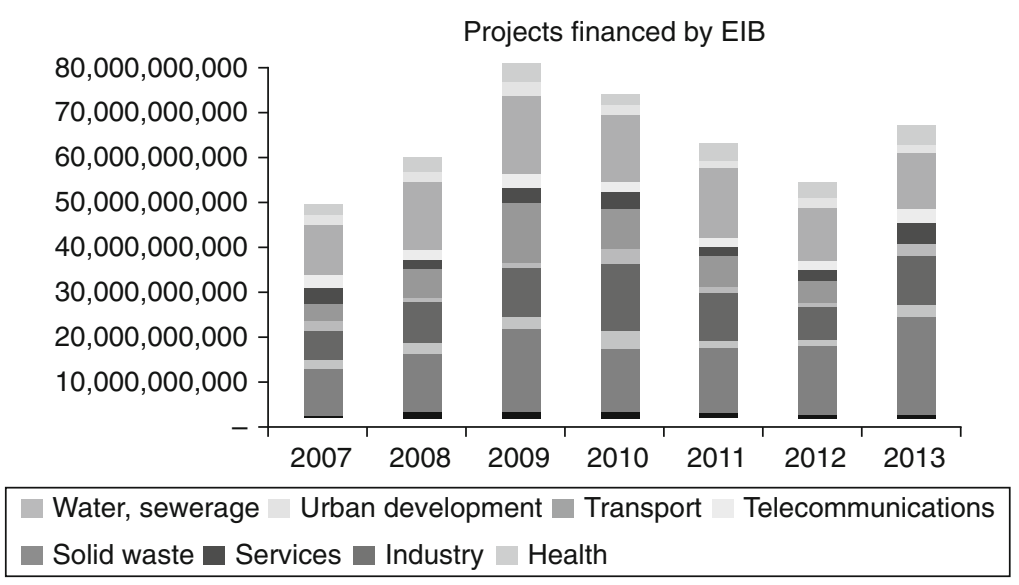

Chart 1.14 Projects financed by EIB

Source: Authors' elaboration on EIB's data (2013).

(8.8 per cent). The EIF is provided with capital of $€ 3$ billion. It uses market instruments to promote the creation and growth of European SMEs, such as venture capital, mezzanine finance and debt instruments (supported by collaterals).

With regard to debt instruments, the EIF operates through credit support activities and guarantees/counterguarantees for loan portfolios and leasing contracts entered by SMEs. The EIF helps the partner financial institutions to facilitate transfer of risk, provide part of the equity and reserve capital and diversify financing sources. EIF's guarantees contribute to strengthen the SMEs access to credit while generating further resources for their development.

The table below illustrates some statistical data related to operations and activities carried out by EIF (Table 1.4 and Chart 1.15).

\subsection{The main financial instruments 2007-2013}

Following decision no. 1639/2006 of the European Parliament and the European Council (24 October 2006), the EU established a Competitiveness and Innovation Framework Programme for the period January 2007 to December 2013. This programme pursues the following objectives:

- Promote the competitiveness of enterprises, in particular SMEs.

- Promote any innovation forms, including eco-innovation. 
- Accelerate the development of a sustainable, innovative and inclusive information society.

- Promote energy efficiency and the use of innovative and renewable energy sources in all sectors, including transports.

The programme at issue is provided with a budget of $€ 3,621,300,000^{35}$ for its implementation.

Table 1.4 Yearly signatures (€ millions)

\begin{tabular}{lrrrrc}
\hline & \multicolumn{5}{c}{ Year } \\
\cline { 2 - 6 } Operational highlights & $\mathbf{2 0 1 3}$ & $\mathbf{2 0 1 2}$ & $\mathbf{2 0 1 1}$ & $\mathbf{2 0 1 0}$ & $\mathbf{2 0 0 9}$ \\
\hline Equity signatures & 1,468 & 1,350 & 1,126 & 930 & 733 \\
Equity catalysed amount & 7,147 & 7,078 & 6,061 & 4,589 & \multicolumn{1}{c}{-} \\
Guarantee signatures & 1,844 & 1,180 & 1,461 & 611 & 191 \\
Guarantee catalysed amount & 8,611 & 5,111 & 7,626 & 3,138 & - \\
Microfinance signatures & 54 & 40 & 67 & 8 & - \\
Microfinance catalysed amount & 201 & 139 & 14 & 32 & - \\
\hline
\end{tabular}

Source: Authors' elaboration on EIF data (2013), Annual report 2013, Imprimerie Centrale, Luxembourg, http://www.eif.org/news_centre/publications/eif_annual_report_2013.pdf.

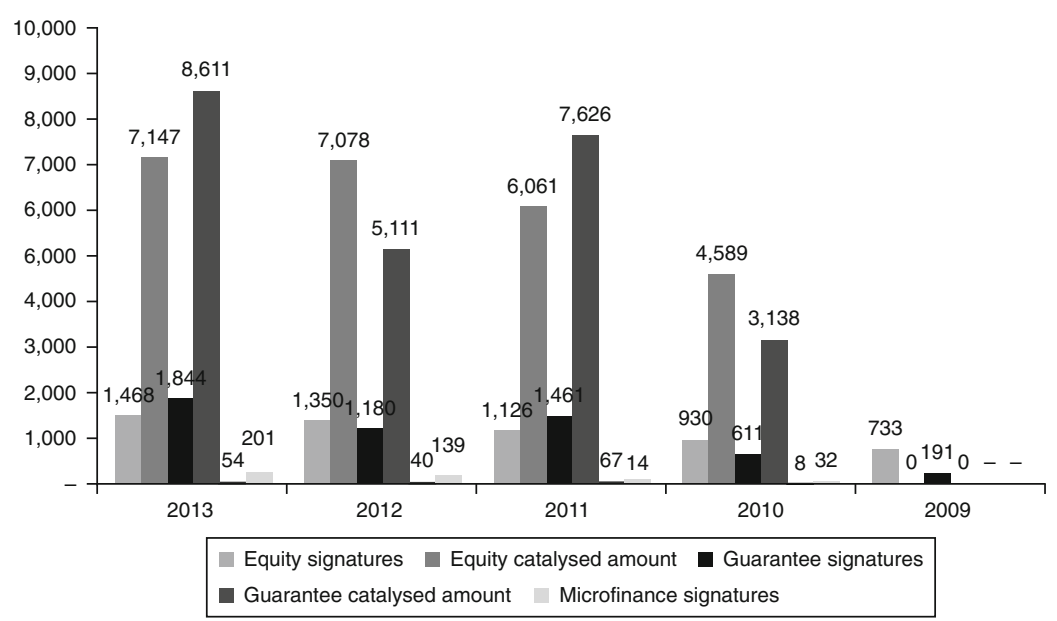

Chart 1.15 Yearly signatures (€ millions)

Source: Authors' elaboration on EIF's data (2013). 
The programme's financial instruments are as follows:

- GIF (Growth and Innovative Facility);

- SMEG (Small Medium Enterprise Guarantee Facility);

- CBS (Capacity Building Scheme).

Table 1.5 describes in detail each of the above financial instruments, including general information on activation date, financing methods, main objectives, statistical data and primary advantages that can be obtained through their use.

\subsection{GIF}

The GIF (Growth and Innovative Facility) contributes to the establishment and financing of SMEs and reduces the lack of equity capital in the European markets. It is managed by the European Investment Fund on behalf of the European Commission and supports innovative and high-growth potential SMEs, favouring those engaged in R\&D and innovation. There might also be co-investments in funds and investment vehicles promoted by intermediaries, including collaboration with national or regional programmes aimed at developing investments into small enterprises. The GIF (EP, 2006, p. 17) ${ }^{36}$ includes two sections that support SMEs in two different stages:

- Section "GIF 1" involves the provision of risk capital for innovative SMEs in their early stages (seeding and start-up). This facility invests in the equity of intermediary capital venture funds and other investment vehicles that, in turn, invest in SMEs no older than ten years, generally during the seeding and start-up phases. EIF usually can invest (EC, 2006) $)^{37}$ in 10-25 per cent of the total equity of the intermediary venture capital funds. In exceptional cases, EIF can invest up to 50 per cent of the total risk capital; this happens for new funds likely to have a particularly strong catalytic role for the development of risk capital markets for specific technologies, in a specific area or for investment instruments of formal investors. The GIF1 can co-invest using the EIF's own resources or other resources managed by the EIF. In both cases, the maximum commitment for a single fund cannot exceed $€ 30$ million (EP, 2006, p. 22). ${ }^{38}$

- The second section, named "GIF 2" (EP, 2006), ${ }^{39}$ concerns the provision of risk capital for SMEs with high growth potential in their expansion phase; the EIF invests in venture capital funds that, in 


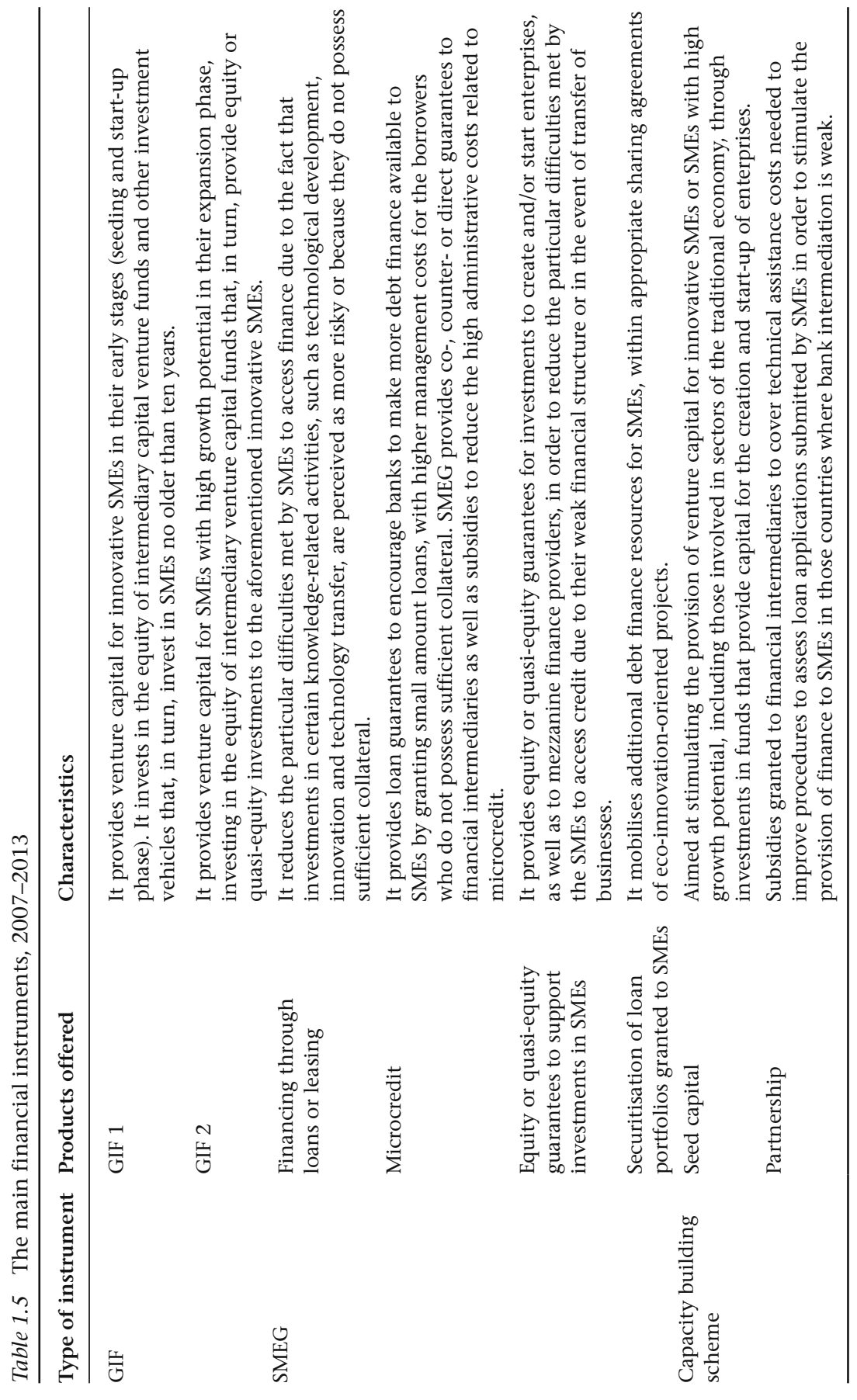


turn, provide equity or quasi-equity investments in the aforementioned innovative SMEs. GIF 2 investments do not support buyout or asset-stripping operations. ${ }^{40}$

\subsubsection{Statistical data}

At the end of December 2012, 34 agreements had been signed. The net amount committed to these funds was $€ 430.5$ million. ${ }^{41}$ A total of 289 SMEs have benefited from investments.

Overview of commitments/deals and agreements/related equity investment and final beneficiaries as of 31 December 2012:42

- EU GIF budgetary commitments since the beginning (2007): $€ 499.77$ million;

- EU GIF net commitments: €430.5 million;

- deals approved by EC as of 31 December 2012 (ECFIN data on deals flow): 36 deals had been approved by the EC with regard to the financial intermediaries (venture capital funds), for a total of $€ 463.8$ million in net commitments from the EU budget, corresponding to a utilisation rate of 98.5 per cent of commitments available for deals (i.e., €470.6 million over the period 2007-2012). Out of these 36 funds, 17 funds have a multicountry focus, and the remaining 19 funds target investments in specific countries. Ten venture capital funds are investing in eco-innovation projects, supported by approved EU investments for a total amount of $€ 147.9$ million (valued at the exchange rate of the reporting date);

- number of signed agreements (by EIF): 34 (out of the 36 funds approved), for a total amount of $€ 430.5$ million);

- including eco-innovation: 7 deals (20.5 per cent), amounting to $€ 124.9$ million (29 per cent).

The stage focus spread of the 34 agreements is indicated in Table 1.6.

Table 1.6 Types of agreements

\begin{tabular}{lr}
\hline$\square$ start-up/early stage & 13 \\
$\square$ technology transfer & 5 \\
$\square$ other (small caps/midmarket/balanced venture capital): & 16 \\
\hline
\end{tabular}

Source: Authors' elaboration on EC data (2013). 
Table 1.7 Number of final beneficiaries (SMEs) as of 31 December 2012

Gearing effect of GIF (target intermediary size/EU GIF net commitments)

Number of final beneficiaries (SMEs)

Contribution to long-term growth prospects of beneficiaries: nearly $95 \%$ of the final beneficiaries interviewed stated that the EIP support had a positive or fairly positive impact on their long-term growth prospects.

Feedback from SMEs on added value, utility and relevance ${ }^{b}$

- Final beneficiaries stating the EU financing scheme was the only option available

- Final beneficiaries stating that they would have received only part of $\quad 23 \%$ the funding needed without the EU financing scheme

Total of beneficiaries indicating that EU support was crucial to finding $\quad 62 \%$ the finance needed

- Leverage effect assessment: final beneficiaries stating that receiving financing from EIP was easier to get additional finance

a2,360.1/430.5; target intermediary (fund) size as of 31 December 2012: €2,360.1 million (Source: EIF CIP GIF Report, 31 December 2012).

${ }^{b} \mathrm{EIP}$ (2011), "Final evaluation final report March 2011", questionnaire on 117 interviewees, pp. $47,56,57$.

Source: Authors' elaboration on EIPC data (2013), http://ec.europa.eu/cip/files/docs/eip-finalevaluation-report_en.pdf.

\subsection{The SMEG}

The SME Guarantee Facility (SMEG) offers guarantees to encourage banks to mobilise additional resources to finance SMEs through loans by reducing their exposure to risk. The SMEG provides co-, counterand direct guarantees to financial intermediaries providing loans, mezzanine finance and microcredit to the SMEs. The SMEG is divided into four sections (loan or leasing guarantees, microcredit, equity and quasi-equity guarantees, securitisation of loan portfolios granted to SMEs), whose operating methods have already been illustrated in Table 1.5 (EP, 2006, p. 26). ${ }^{43}$

\subsubsection{Statistical data}

At the end of 2012, 62 agreements with 45 financial intermediaries had been signed under this facility. In total, 256341 loans were provided to 218,843 SMEs. 
Table 1.8 Amount of commitments/guarantees

\begin{tabular}{ll}
\hline Commitments/guarantees & Amount \\
\hline EU SMEG budgetary commitments since beginning & $€ 510.88$ million \\
(Source: ECFIN budget figures) & \\
EU SMEG total loan amount & $€ 13,353.3$ million \\
EU SMEG guarantee & $€ 7,420.3$ million \\
SMEG guarantee cap amount & $€ 460.1$ million \\
\hline
\end{tabular}

Source: Authors' elaboration on EIF data (2013), Entrepreneurship and Innovation Programme Committee, http://ec.europa.eu/cip/files/cip/eip_performance_report_2007-2013_en.pdf.

\section{Table 1.9 Output SMEG}

Number of signed agreements (by EIF) 62

Number of agreements brought about by SMEG windows

\section{Loan window}

Microcredit window

Equity/quasi-equity window

Number of SMEs benefiting as of 31 December 2012

Number of related loans as of 31 December 2012

Source: Authors' elaboration on EIF data (2013), Entrepreneurship and Innovation Programme Committee, http://ec.europa.eu/cip/files/cip/eip_performance_report_2007-2013_en.pdf.

Table 1.8 shows an overview of commitments/guarantees/deals and agreements/related loans and final beneficiaries financed by SMEG as of 31 December 2012.

At the end of December 2012, the EC approved deals with 46 financial intermediaries from 23 countries (including 16 from 8 new member states, one from Norway, one from Serbia and Montenegro, two from Croatia and four from Turkey), with a total of $€ 482.9$ million from the budget for guarantees or counterguarantees (Table 1.9).

Table 1.10 shows the results in terms of contributions made to longterm growth prospects of final beneficiaries/final beneficiaries' statement on the utility of the programme.

\subsection{The CBS}

The Capacity Building Scheme (CBS) (EP, 2006, p. 26) ${ }^{44}$ is managed in collaboration with a number of international financial institutions, including the European Bank for Reconstruction and Development (EBRD), the EIB, the European Investment Fund and the Council of 
Table 1.10 SMEG results

Gearing effect EU guarantee/guarantee cap amount ${ }^{a}$ 16.1

Leverage (total loan amount/guarantee cap amount ${ }^{b}$

Number of final beneficiaries (SMEs)

The target of $315,750 \mathrm{SMEs}^{c}$ benefiting from the EIP financial instruments by the end of the programme seems therefore achievable (2013)

- Contribution to long-term growth prospects of beneficiaries: $3 / 4$ of all interviewed final beneficiaries stated that the EIP support had a positive or fairly positive impact on their long-term growth prospects

- Feedback from SMEs on added value, utility and relevance ${ }^{d}$ :

$\square$ Final beneficiaries stating the EU financing scheme was the only $\quad 46 \%$ option available

$\square$ Final beneficiaries stating that they would have received only part of the funding needed without the EU financing scheme

Total of beneficiaries indicating that EU support was crucial to find $\quad 64 \%$ the finance needed

$\square$ Leverage effect assessment: final beneficiaries stating that receiving $\quad 42 \%$ financing from EIP was easier than accessing additional finance

${ }^{a}$ EU guarantee/guarantee cap amount = 7,420.3/460.1; these are the "gearing effect" figures officially released by the EIF (Source: EIF SMEG 2007 Report, 31 December 2012).

${ }^{b}$ For agreements signed by EIF under SMEG, as of 31 December 2012: Total loan amount/ guarantee cap amount $=13,353.3 / 460.1$ (Source: EIF SMEG 2007 Report, 31 December 2012).

'EIP (2013), "Final evaluation final report", March 2011, p. 51.

${ }^{d}$ EIP (2013), "Final evaluation final report", March 2011, questionnaire on 117 interviewees, p. $47,56,57$.

Source: Authors' elaboration on EIF data (2013).

Europe Development Bank (CEB). The CBS pursues the following objectives:

- Improve technical skills on investments, fund technology and those of other financial intermediaries investing in innovative or high growth potential SMEs.

- Stimulate credit supply to the SMEs by improving assessment procedures to evaluate loan applications submitted by SMEs.

The CBS comprises two parts: seed capital and partnership.

The seed capital action provides grants aimed at stimulating the supply of venture capital to innovative SMEs and other SMEs with high growth potential, including those operating in traditional sectors of the economy, by providing grants to venture capital funds investing in the 
creation or support of start-ups or similar organisations. Grants can be provided also for the long-term recruitment of staff or staff with specific investment or technology expertise.

The partnership action provides grants to financial intermediaries to cover the costs of the technical assistance needed to improve their assessment procedures to evaluate loan applications submitted by SMEs in order to stimulate the supply of financing to SMEs in those countries where bank intermediation is weak. For partnership action purposes, bank intermediation in a given country is deemed weak when the domestic credit, expressed as a percentage of gross domestic product of a country, is well below the EU average, according to data of the European Central Bank or the International Monetary Fund.

The partnership action supports the credit lines or risk-sharing that the international financial institutions grant to their partners (banks or financial institutions) in eligible countries. A significant portion of the action is aimed at improving the capacity of banks and other financial intermediaries to assess the loans' commercial feasibility.

\subsection{Financial engineering instruments}

To ensure a more efficient and sustainable use of the structural funds and cohesion funds in the period 2007-2013, the European Commission activated various programmes and numerous financial instruments. Financial engineering instruments ${ }^{45}$ are an innovative form provided by the structural funds to achieve the cohesion policy objectives, as they are an integral part of the strategy aimed at promoting long-term sustainable growth in the European regions. For such purpose, the European Commission implemented a number of financial instruments in collaboration with EIBI, EBRD and CEB. These instruments are forms of financial support different from grants. Art. 44 (EC, 2006) ${ }^{46}$ of General Regulation no. 1083/2006 EC is the main source regulating the various aspects of financial engineering instruments. The financial engineering instruments are the following: JEREMIE and JESSICA.

\subsubsection{JEREMIE}

JEREMIE (Joint European Resources for Micro to Medium Enterprises) is an initiative of the European Commission developed together with the European Investment Funds and the European Investment Bank. It is an opportunity offered to all EU regions to use their structural fund allocations to finance measures and programmes aimed at supporting the development of enterprises through the use of financial engineering 
instruments. Within the JEREMIE initiative, national and regional authorities may choose to use the financial resources allocated by the European Regional Development Fund (ERDF) in the forms of equity, loans and/or guarantees.

Unlike the assistance traditionally provided through grants, which can be spent only once, the financial instruments activated through JEREMIE have the advantage of being revolving; hence, a pool of funds can be reused several times. While global grants are reimbursements of expenditures incurred by managing authorities according with the relevant invoices, JEREMIE is instead an advance payment, according to the operations and uses planned.

JEREMIE (EIF, 2012) ${ }^{47}$ provides for three main services:

- counselling and technical assistance;

- investments in equity and venture capital;

- loan guarantees.

The implementation of the initiative is entrusted to the individual managing authorities; they choose a fund holder, which shall subsequently select the financial intermediaries channelling the resources (revolving resources) to the enterprises. The JEREMIE programme is dedicated to the small and microenterprises controlled or owned by private subjects or enterprises in the final stage of their privatisation process. However, exclusions concern SMEs involved in the following businesses: real estate, banking, insurance, financial intermediation, gaming and all those enterprises excluded from the EIB and EIF lists. The EU member states can implement the JEREMIE initiative by creating holding funds financed by the structural funds. The management of such funds can be assigned to the EIF or other financial institutions according to the applicable EU legislation on structural funds (EC Regulation no. 1083/2006 and Executive Regulation no. 1828/2006). The managing authorities, therefore, can assign their management directly to the EIF or any national institutions or financial institutions by means of a tender. Holding funds can be set up as bank accounts managed in name and on behalf of the managing authorities or as independent legal entities (with the establishment of a specific organisation). The choice of the most suitable legal form depends on the complexity of the JEREMIE holding funds and applicable national legislation. The JEREMIE ${ }^{48}$ initiative combines contributions from the European Regional Development Fund with loans and other forms of financing to support the creation and development of small, medium-sized and microenterprises within 
the regional policy of the European Union. Moreover, JEREMIE supports the transfer of technology and partnerships between enterprises, universities and R\&D centres by improving access to microcredit for all those subjects excluded from the traditional lending system. Finally, the financing through instruments under the JEREMIE initiative can be combined with other instruments to support enterprises and institutions financed by the structural funds.

\subsubsection{The advantages of the JEREMIE programme}

Here follows a detailed description of the main advantages of using JEREMIE:

- Flexibility: the contributions from the operational programmes to the JEREMIE holding funds may be advanced on a provisional basis by the European Regional Development Fund (ERDF) and the European Social Fund (ESF), thus allowing the managing authorities to allocate the resources more flexibly; the contributions from the structural funds to the holding funds must be invested in the SMEs by 2015 .

- Advantages of a portfolio-approach: the holding funds may allocate the resources in a flexible way by using several financial instruments tailored to the specific needs of particular countries or regions. The nature of holding funds with multiple compartments facilitates the diversification of risk and enhances the effectiveness of their investments in businesses.

- Reuse of funds: Holding funds are revolving funds, fed by the repayments made by the financial intermediaries, which are the reinvested in SMEs. Compared to the traditional assistance provided through grants, the EU structural funds thus are designed to provide a longlasting and continuous support to the European SMEs.

- Leverage: one of the most relevant advantages of using JEREMIE is the capacity of boosting financial resources, with regard both to the holding funds, thanks to capital contributions from the financial institutions, and to the financial instruments through public-private co-financing, for instance in collaboration with the EIB.

\subsubsection{JESSICA}

JESSICA (Joint European Support for Sustainable Investment in City Areas) is an initiative of the EC for sustainable investments in city areas developed in cooperation with the EIB and the Council of Europe Development 
Bank (CEB). This programme sees also the collaboration of the member states, regions, provincial and municipal authorities and other public and private investors in the implementation of the projects. Partnerships are conducted in compliance with the institutional, legal and financial responsibilities of each category of subjects. In this way, the structural fund allocations can be used in innovative ways to support urban development projects and do not represent a source of additional funding. Public-private partnerships are intended for the use and development of innovative financial engineering instruments suitable to produce repayable investments or guarantees for repayable investments or both. Thanks to this initiative, the managing authorities of the member countries, in particular regions, are authorised to use their structural fund contributions to develop urban areas, choosing to invest them in urban development funds (UDF) ${ }^{49}$ or, alternatively, channelling them in holding funds (HF), which are set up to invest in several UDFs. These funds are financial engineering instruments that must be set up as independent legal entities or as "independent capital", accounted for separately within existing financial institutions. They can be public, private or public-private funds; they are not governed by a specific regulatory framework of their own within the European regulations for the structural funds but can invest directly in public-private partnerships and other urban projects included in an integrated plan for the sustainable urban development. JESSICA is designed for urban renewal activities, whose returns should seek to preserve the value of the investments over time and allow, through recycling of funds, reuse of the initial contributions for other similar projects. This initiative, therefore, supports the development of urban areas in their environmental, social, institutional and governance dimension through innovative methods of strategic analysis and project assessment. Physical, human and business capital is all integrated in a multidimensional and flexible dimension, with the aim of creating "sustainable communities".

The implementation of the initiative provides for the creation of an integrated plan for sustainable urban development, which is a system of interconnected interventions aimed at improving economic, physical, social and environmental conditions of city areas. As a whole, the plan should achieve better results than those that would be obtained by the single parts if independently implemented. It should not be regarded, therefore, as a closed structure but rather as a process suitable to amendments and integrations.

It is therefore essential to prepare medium to long-term plans to ensure sustainable development and the coherence of investments and their 
environmental quality ${ }^{50}$ (EIB, 2008). The integrated plans must lead not just to the restoration of the territorial characteristics but to a true rebirth of the territory, with positive impact on urban and extraurban area development.

Rules on the eligibility of project expenditure, using JESSICA, are the same as those on the use of the structural funds as a whole and also need to take account of any national constraints. Apart from specific non-eligible items listed in the regulation, such as housing in some of the member states, JESSICA may allow for more flexible management of projects, respecting at the same time the eligibility rules, provided always that the projects being supported form part of Integrated Plans for Sustainable Urban Development. ${ }^{51}$ Ineligible expenditure components might, for example, be included as a part of a larger, multisector urban development project, provided that sufficient additional funding is attracted from other public or private sources. Specifically, JESSICA promotes sustainable urban development by supporting projects in the following areas:

- urban infrastructure, including transport, water/waste water, energy;

- heritage or cultural sites for tourism purposes or other sustainable uses;

- redevelopment of brownfield sites, including site clearance and decontamination;

- creation of new commercial floor space for small and medium-sized enterprises (SMEs), IT and/or R\&D sectors;

- university buildings, including medical, biotech and other specialised facilities;

- energy efficiency improvements.

Taking a look at the advantages of the JESSICA programme, we can identify a leverage effect obtained by attracting and combining structural funds with private funding sources and supporting the creation of PPP (public-private partnerships) as well as a market-oriented approach, which facilitates the effective implementation of projects. The opportunity to rely on the professional expertise of international financial institutions and specialised investment funds facilitates the development and modernisation of local financial markets, thus attracting new types of investors. With regard to the use of the European structural funds, which reduce the risks related to the complexity of the projects for sustainable urban development, JESSICA makes available a permanent financial instrument, as it allows receiving payments in advance 
as well as the reuse of funds. Long-term sustainability of investments is boosted by the revolving nature of the EU structural funds and the possibility of reusing the funds already obtained, thanks to the reinvestments of profits generated by the projects. Return on investments generated by the investments in projects is preferentially allocated to private investors and only at a later time to other public partners. In compliance with the national constraints, this instrument provides for the flexibility needed both for defining the general objectives and areas of interventions and for use of resources. It leads to the achievement of higher returns on investments thanks to the configuration of a global package of projects, which are coordinated with other national and regional policies. Among the other advantages in terms of resource management offered by this initiative is reduction of risk of automatic decommissioning of resources. The ERDF allocations to the Funds for Urban Development are not subject to potential limits and restrictions related to the calculation of $N+2^{52}$ until 2013 (evidence of the actual disbursement of the funds by the UDF shall be submitted during the final certification phase by December 2015).

Resources to be allocated to interventions are made available and can be used immediately. Thanks to the support offered by the EIB, which provides specialised consulting services, JESSICA offers the opportunity to attract investments also from other international institutions, such as the Council of Europe Development Bank (CEB), which already agreed to join the programme. Last but not least, development and consolidation of a European market of qualified operators dedicated to urban renewal results in the definition of clear and standardised procedures, thus facilitating the inclusion of the JESSICA initiative in the operational programmes (on a national and regional level) and their implementation.

\subsubsection{JASPERS}

JASPERS $^{53}$ (Joint Assistance to Support Projects in European Regions) is a technical assistance facility developed in partnership between the European Commission (Directorate General for Regional Policy), the European Bank for Reconstruction and Development and the Kreditanstalt fur Wiederaufbau (KFD), dedicated to the 12 member countries which joined the EU in 2004 and 2007 (Bulgaria, Czech Republic, Cyprus, Estonia, Hungary, Latvia, Lithuania, Malta, Poland, Romania, Slovakia and Slovenia) and, from 2011, Croatia, in anticipation of its inclusion in the EU, which took place in July 2013. It provides the EU member states 
concerned with the technical support they need to prepare high-quality major projects, which will be co-financed by the structural funds and the cohesion fund. Specifically, this initiative

- provides technical assistance aimed at improving the preparation of investment projects eligible for funding under the EU structural funds for the period 2007-2013;

- provides technical assistance to the EU state members concerned to enable them to better prepare major infrastructure projects. In particular, JASPERS advice can cover project preparation (e.g. costbenefit analysis, financial analysis, environmental issues, procurement planning), review of documentation (feasibility studies, grant applications, etc.) as well as advice on compliance with EU law (environmental, competition, etc.);

- coordinates, develops and re-examines the project structures, eliminating potential bottlenecks, filling gaps and identifying those issues that have not been fully resolved by the beneficiaries states, such as applications for EU grants in PPP projects, issues related to state aid and environmental impact assessment;

- operates following the country action plans prepared annually for each member in cooperation with the beneficiary state concerned and the European Commission. A managing authority acts as a central coordinator for each country, and it can request assistance from JASPERS. JASPERS professionals (EIB, 2012) ${ }^{54}$ provide technical assistance for all the phases of the projects since their seeding stage.

During the process of preparing the annual action plans, JASPERS works in close cooperation with beneficiaries, managing authorities and relevant intermediate bodies. The member states remain the owners of the projects, and the grant application process remains always their responsibility. There is no obligation of JASPERS beneficiaries to borrow from EIB, EBRD or KFW. The JASPERS ${ }^{55}$ structure is based on five sectors of activity: air, maritime and public transport, knowledge economy and energy, water and waste and roads. The sector-based structure meets JASPERS operational needs and ensures consistency in advice delivered across the beneficiaries' countries.

JASPERS mainly targets assistance on major infrastructure projects with total costs exceeding €25 million for environmental projects and $€ 50$ million for transport and other infrastructure projects, which can be supported also by the EU cohesion fund. 
Statistical data

Table 1.11 JASPERS performance

\begin{tabular}{|c|c|c|c|c|c|c|c|c|c|}
\hline & $\begin{array}{l}\text { Total } \\
2006 \text { to } \\
\text { date }\end{array}$ & 2006 & 2007 & 2008 & 2009 & 2010 & 2011 & 2012 & 2013 \\
\hline $\begin{array}{l}\text { Number of } \\
\text { assignment s } \\
\text { completed (\#) }\end{array}$ & 795 & 3 & 22 & 82 & 133 & 159 & 142 & 116 & 138 \\
\hline $\begin{array}{l}\text { Number of } \\
\text { JASPERS- } \\
\text { supported } \\
\text { applications } \\
\text { submitted to the } \\
\text { commission (\#) }\end{array}$ & 407 & 0 & 5 & 30 & 59 & 86 & 62 & 76 & 89 \\
\hline $\begin{array}{l}\text { Number of } \\
\text { JASPERS- } \\
\text { supported } \\
\text { applications } \\
\text { approved by the } \\
\text { commission (\#) }\end{array}$ & 310 & 0 & 0 & 10 & 35 & 58 & 68 & 53 & 86 \\
\hline
\end{tabular}

Source: Authors' elaboration on JASPERS annual report (2013).

Table 1.12 JASPERS budget, 2006-2013 (€ millions)

\begin{tabular}{lrrrrrrrr}
\hline $\begin{array}{l}\text { Total 2006 } \\
\text { to date }\end{array}$ & 2006 & 2007 & 2008 & 2009 & 2010 & 2011 & 2012 & 2013 \\
\cline { 2 - 8 } & 3.6 & 17.8 & 21.2 & 23.5 & 30.2 & 31.9 & 30.4 & 31.6 \\
\hline
\end{tabular}

Source: Authors' elaboration on JASPERS annual report (2013), www.jaspers-europa-info.org/ attachments/article/161/JASPERS\%20Annual\%20Report\%202013_en.pdf.

\subsubsection{JASMINE}

JASMINE $^{56}$ (Joint Action to Support Microfinance Institutions), the fourth joint initiative of the EC, the EIB and the EIF, is a pilot programme initiated in 2008 whose objective is to develop the microcredit market in the European Union by providing financial support (through loans and equity) and technical assistance, dedicated to non-bank microcredit operators. This project complements the action started by the JEREMIE programme. JASMINE can be considered the operational outcome of the EC communication of 13 November 2007, which proposed the "European initiative for the development of 


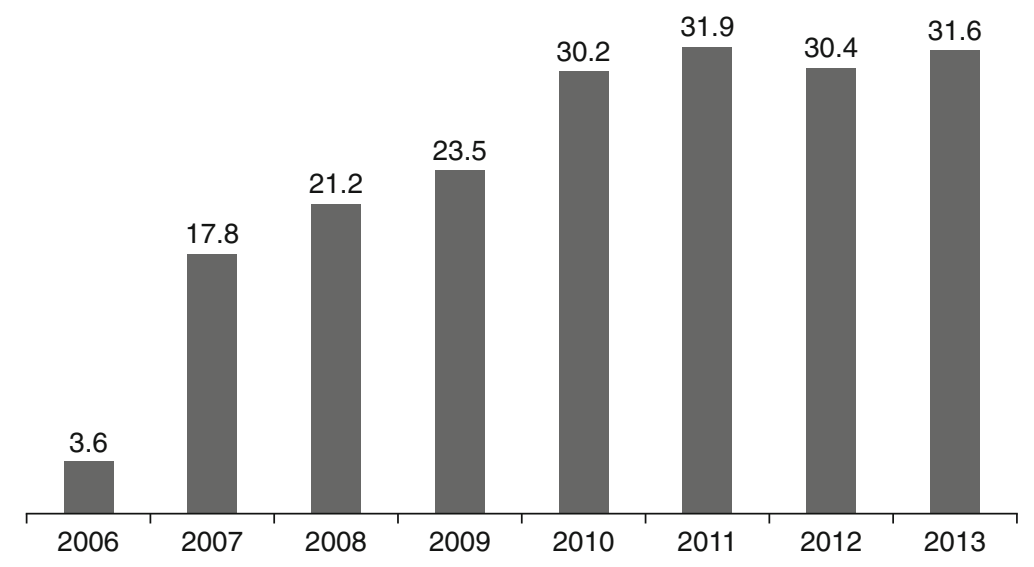

Chart 1.16 JASPER budget, 2006-2013 (€ millions) Source: Authors' elaboration JASPERS annual report (2013).

microcredit in support of growth and employment" (EC, 2007). ${ }^{57}$ JASMINE was created to

- support the development of microcredit providers and microfinance institutions (MFIs) in various areas, such as institutional governance, information systems, risk management and strategic planning;

- help these intermediaries become sustainable operators on commercial terms.

The project is financed by the Directorate General of EU Regional Policies in the amount of $€ 50$ million and is made available free of charge to the beneficiaries. This facility is dedicated to new and non-bank MFIs and provides

- technical assistance;

- information and publicity regarding the initiative for member states, regions, banks and MFIs in general;

- technical manuals, guides, software and organisation of seminars and conferences;

- improved access to finance.

The EIF was entrusted with the task of providing financial support and technical assistance to non-bank MFIs. Financial support (with a budget 
of approximately €20 million) can take the form of co-investments (in collaboration with banks, MFIs, development agencies, etc.) dedicated to microcredit operators that have almost achieved self-sustainability $^{58}$ and/or in a growth phase. Technical assistance (with a budget of $€ 30$ million) is aimed at increasing the reliability of the MFIs, facilitating access to finance and providing institutions with a free-of-charge assessment of their activity, organisation and structure.

To participate in the programme, the MFIs shall meet the following specific requirements:

- They must operate in EU member states.

- They must operate in the microcredit for at least two years.

- They must have more than 150 active customers during the last year.

- They must be engaged in social development programmes.

- They must provide evidence of their internal strategy.

Following the selection of applicants, in collaboration with the two rating agencies involved in the project, "MicroFinanza Rating" 59 and "Planet Rating", ${ }^{60}$ assessments and estimates of the activities carried out by the MFIs are performed. Upon conclusion of such operations, the selected beneficiaries may benefit from the following services made available free of charge:

- Either an evaluation/diagnosis of their structure, organisation or operating mode or an institutional rating performed by a specialised rating agency.

- Consulting or training of a maximum duration of 12 days for the technical staff and the management provided by expert consultants of the Microfinance Centre.

From 2010 to 2013, 70 microfinance and microcredit institutions (EC, $2013)^{61}$ were supported through this programme; as already mentioned, once selected as potential beneficiaries, the MFIs could enjoy tailored consulting, training and rating services free of charge. Implementation of these three EU initiatives proved essential for the creation and development of a healthy environment for the growth of microcredit in Europe. Moreover, these programmes prompted many institutions to improve their businesses, especially in light of the possibility of accessing the EU structural funds and thanks to greater availability of economic resources to fund valid business projects. 


\section{Summary of data collected on financial engineering instruments}

At the end of 2012, a total of 870 specific loan guarantees, equity/venture capital and other funds were set up, of which 816 were for enterprises, 38 for urban development and 16 for energy efficiency/renewable energies. Compared to the data for 2011, the total number of specific funds reported for 2012 increased by 324 funds (see Table 1.12). ${ }^{62}$

Table 1.13 Number of FEIs reported at the end of 2011 and 2012

\begin{tabular}{|c|c|c|c|c|c|c|c|c|c|}
\hline \multicolumn{6}{|c|}{ Summary of data for 2012} & \multicolumn{4}{|c|}{ Summary of data for 2011} \\
\hline 1 & 2 & 3 & 4 & 5 & 6 & 7 & 8 & 9 & 10 \\
\hline No. & $\begin{array}{l}\text { Member } \\
\text { states }\end{array}$ & $\begin{array}{c}\text { No. of } \\
\text { FEIs }\end{array}$ & $\begin{array}{c}\text { of } \\
\text { which } \\
\text { HF }\end{array}$ & $\begin{array}{c}\text { of which } \\
\text { specific } \\
\text { funds } \\
\text { with a } \\
\text { HF }\end{array}$ & $\begin{array}{l}\text { of which } \\
\text { specific } \\
\text { funds } \\
\text { without } \\
\text { a HF }\end{array}$ & $\begin{array}{l}\text { No. of } \\
\text { FEIs* }\end{array}$ & $\begin{array}{c}\text { of which } \\
\text { HF }\end{array}$ & $\begin{array}{l}\text { of which } \\
\text { specific } \\
\text { funds } \\
\text { with a } \\
\text { HF }\end{array}$ & $\begin{array}{l}\text { of which } \\
\text { specific } \\
\text { funds } \\
\text { without } \\
\text { a HF }\end{array}$ \\
\hline 1 & AT & 2 & & 0 & 2 & 2 & 0 & 0 & 2 \\
\hline 2 & $\mathrm{BE}$ & 9 & 0 & 0 & 9 & 9 & 0 & 0 & 9 \\
\hline 3 & BG & 9 & 2 & 6 & 1 & 5 & 2 & 3 & 0 \\
\hline 4 & $\mathrm{CY}$ & 4 & 1 & 3 & 0 & 4 & 1 & 3 & 0 \\
\hline 5 & $\mathrm{CZ}$ & 4 & 2 & 0 & 2 & 3 & 1 & 0 & 2 \\
\hline 6 & $\mathrm{DE}$ & 41 & 0 & 0 & 41 & 42 & 4 & 4 & 34 \\
\hline 7 & DK & 6 & 0 & 0 & 6 & 6 & 0 & 0 & 6 \\
\hline 8 & $\mathrm{EE}$ & 6 & 0 & 0 & 6 & 6 & 0 & 0 & 6 \\
\hline 9 & EL & 26 & 4 & 21 & 1 & 14 & 4 & 10 & 0 \\
\hline 10 & ES & 15 & 6 & 7 & 2 & 9 & 4 & 4 & 1 \\
\hline 11 & FI & 1 & 0 & 0 & 1 & 1 & 0 & 0 & 1 \\
\hline 12 & FR & 95 & 2 & 17 & 76 & 111 & 3 & 4 & 104 \\
\hline 13 & $\mathrm{HU}$ & 185 & 1 & 183 & 1 & 3 & 1 & 1 & 1 \\
\hline 14 & IT & 95 & 13 & 15 & 67 & 80 & 14 & 14 & 52 \\
\hline 15 & LT & 33 & 4 & 28 & 1 & 29 & 4 & 24 & 1 \\
\hline 16 & LV & 10 & 1 & 5 & 4 & 9 & 1 & 5 & 3 \\
\hline 17 & MT & 2 & 1 & 1 & 0 & 2 & 1 & 1 & 0 \\
\hline 18 & NL & 8 & 1 & 2 & 5 & 5 & 0 & 0 & 5 \\
\hline 19 & PL & 247 & 16 & 128 & 103 & 139 & 13 & 54 & 72 \\
\hline 20 & PT & 50 & 3 & 34 & 13 & 19 & 3 & 7 & 9 \\
\hline 21 & $\mathrm{RO}$ & 3 & 1 & 2 & 0 & 3 & 1 & 2 & 0 \\
\hline 22 & SE & 11 & 0 & 0 & 11 & 11 & 0 & 0 & 11 \\
\hline 23 & SI & 4 & 1 & 2 & 1 & 10 & 1 & 8 & 1 \\
\hline 24 & SK & 1 & 1 & 0 & 0 & 1 & 1 & 0 & 0 \\
\hline 25 & UK & 73 & 10 & 27 & 36 & 68 & 9 & 27 & 32 \\
\hline \multirow[t]{2}{*}{26} & $\mathrm{CBC}$ & 0 & 0 & 0 & 0 & 1 & 0 & 0 & 1 \\
\hline & Total & 940 & 70 & 481 & 389 & 592 & 68 & 171 & 353 \\
\hline
\end{tabular}

Source: Authors' elaboration on EC data (2013), "Summary of data on the progress made in financing and implementing financial engineering instruments co-financed by structural funds", http://ec.europa.eu/regional_policy/thefunds/instruments/doc/summary_data_ fei_2012.pdf. 
Although the total number of specific funds reported in 2012 increased by 66 per cent, the share of the three types of funds ${ }^{63}$ remained the same - 94 per cent for funds targeting enterprises, 4 per cent for funds for urban development and 2 per cent for funds operating in the area of energy efficiency/renewable energies. Of all specific funds, 389 were implemented directly (without a holding fund), and 481 were implemented through 70 holding funds.

At the end of 2012, the total value of the 159 ERDF and 16 ESF operational programmes contributions paid by managing authorities to financial engineering instruments amounted to €12,558.23 million, of which $€ 8,364.58$ million were structural funds. The total value of contributions paid to the holding funds amounted to $€ 5,957.16$ million, including $€ 4,314.48$ million of 21 structural funds and $€ 1,642.68$ million of the national co-financing. This represents 86 per cent of the OP contributions committed in the funding agreements signed between managing authorities and holding funds. Of $€ 5,957.15$ million of OP contributions paid to the holding funds, almost a half (€2,812.20 million) was subsequently transferred to the specific funds for enterprises, meaning that $€ 3,144.88$ million of OP contributions (including $€ 2,340.53$ of structural funds and $€ 801.30$ million of national co-financing) remained at the level of holding funds at the end of 2012. In addition, €6,601.07 million of OP contributions, with €4,050.10 million of structural funds and $€ 2,550.97$ million of the national co-financing was paid directly from managing authorities to specific funds set up without a holding fund. The amounts paid to specific funds set up without a holding fund at the end of 2012 represent 62 per cent of amounts committed in legal agreements. In total, €9,413.35 million of OP contributions (including €6,024.05 million of structural funds) reached specific funds and was available to support final recipients. At the end of the reporting period (31 December 2012), 37 per cent of this amount ( $€ 4,684.33$ million) was invested in final recipients. The overall absorption at the level of final recipients increased by more than 20 per cent for OP contributions and almost 30 per cent for the structural funds part in comparison to the data reported for 2011.

\subsection{COSME 2014-2020}

COSME $^{64}$ (Competitiveness of Enterprises and Small and Medium-Sized Enterprises) is the new EU programme for the competitiveness of enterprises and SMEs for the period 2014-2020. In particular, the programme is intended to facilitate SMEs' access to finance, improve their competitiveness on the European and international markets and encourage the development of an entrepreneurial culture. 
In addition, COSME intends to stimulate the creation of new enterprises and targets businesses of all industrial, manufacturing and service sectors, including tourism.

The programme provides for specific and relevant financial instruments, for credit and guarantees, in the early stages of growth and development of small and medium-sized enterprises. The COSME programme is provided with a budget of $€ 2.298 .243$ million (EP and EC, 2013) ${ }^{65}$ at current prices for its implementation, of which no less than 60 per cent is dedicated to financial instruments. In fact, almost $€ 1.4$ billion of the COSME budget is dedicated to fund loans and venture capital in addition to national financial support programmes. In particular, the COSME programme will provide guarantees and counterguarantees to loans granted to SMEs and will offer an improved access to venture capital through a financial facility, with a particular focus on the SMEs' stages of growth and expansion. The financial instruments provided by the COSME programme, in accordance with Title VIII of Regulation (UE and Euratom) no. 966/2012, are used to facilitate access to credit for SMEs during the start-up, growth and transfer phases. The financial instruments under the programme may take the forms of equity and guarantees. The allocation of the funds to the various instruments takes into account the demand of the financial intermediaries. Financial instruments for the SMEs can be combined and integrated with the following:

- Other financial instruments established by the member states and the relevant managing authorities and funded with national or regional funds or included in activities financed by EU structural funds, pursuant to art. 38, paragraph 1, letter a), of EU Regulation no. 303/2013.

- Other financial instruments established by the member states and the relevant managing authorities and funded with national or regional funds not included in activities financed by EU structural funds.

- EU subsidies, including within the framework of this regulation.

\subsection{EFG}

The Equity Facility Growth (EFG) is a window of the Single EU Equity Financial Instrument, which supports EU enterprises' growth and research and innovation (R\&I) from the early stage, including seed, up to the expansion and growth stage. The Single EU Equity Financial Instrument enjoys financial support from the programmes Horizon 2020 and COSME. EFG invests in selected funds that provide venture 
capital and mezzanine finance, such as subordinated and participating loans, to expansion and growth-stage SMEs, in particular those operating across borders, with the possibility of investing in early-stage funds as well as providing equity for R\&I within the framework of the Horizon 2020 programme and co-investment instruments for informal investors (business angels). ${ }^{66}$ In case of early-stage investments, the EFG investments (EP and EC, 2013, p. 43) ${ }^{67}$ cannot exceed 20 per cent of the total $\mathrm{EU}$ investment. Exceptions are represented by stage funds and funds of funds, where the EFG investment and the equity facility for R\&I, within the framework of the Horizon 2020 programme, are provided on a pro rata basis, according to the funds' investment policies.

The European Commission may decide to modify the 20 per cent limit depending on the evolution of market conditions. EFG support can take the form of one of the following investments:

- Directly from the European Investment Fund or other entities entrusted with the EFG implementation by the Commission.

- From funds of funds or other investment instruments that invest in cross-border projects, created by the European Investment Fund or other entities (including public and private sector managers) entrusted with the implementation of the EFG by the commission along with public and/or private financial institutions. EFG invests in intermediate venture capital funds, including funds of funds, which invest in expansion and growth SMEs. The investments under EFG are long term, namely investments in venture capital funds usually between 5 and 15 years. In any case, the duration of the investments under EFG cannot exceed 20 years from the signing of the agreement between the European Commission and the entities entrusted with their implementation.

\subsection{LGF}

The Loan Guarantee Facility (LGF; EP and EC, 2013, p. 43) ${ }^{68}$ provides

- counterguarantees and other risk-sharing agreements for guarantee schemes, including co-guarantee, if applicable;

- direct guarantees and other risk-sharing agreements for other financial intermediaries that comply with eligibility criteria.

The LGF is a window of the Single EU Debt Financial Instrument, which supports European enterprises' growth and innovation by using the same implementation mechanism of the section dedicated to SMEs willing to 
use the debt facility for R\&I within the Horizon 2020 programme (RSI II). The LGF includes the following:

- Guarantees for debt financing (including subordinated and participating loans, leasing or bank guarantees) that reduce the difficulties faced by SMEs in accessing vital credit as the investments are perceived as more risky or because enterprises do not have sufficient collateral.

- Securitisation of SME debt finance portfolios, which mobilise additional resources to finance SMEs through lending, within adequate risk-sharing agreements with the relevant institutions. The support to such securitisation operations is conditional upon a commitment by the institutions at issue to use a significant portion of the remaining liquidity or the mobilised capital to grant new loans to SMEs within a reasonable time.

The amounts of the new loans are determined according to the risk amount of the portfolios guaranteed and are negotiated on an individual basis with each institution, including the repayment terms. LGF is directly managed by the European Investment Fund or other entities entrusted with its implementation by the European Commission. The maximum duration of guarantees individually granted under LGF cannot exceed ten years. Eligibility of each intermediary for the LGF facility is assessed according to their activities and effectiveness in supporting SME access to finance for profitable projects. LGF can be used by intermediaries that support enterprises, among other things, to access debt finance to fund acquisition of tangible and intangible assets, working capital and transfer of businesses. Eligibility criteria related to the securitisation of SME debt finance portfolios include individual transactions, transactions with multiple partners and multinational transactions. Eligibility is assessed according to the best practices on the market, in particular with regard to credit quality and risk diversification of the securitised portfolios. Apart from securitised loan portfolios, the LGF covers loans up to $€ 150,000$ and with a minimum maturity of 12 months.

LGF also covers loans exceeding €150,000 when the SMEs that meet eligibility criteria according to the COSME programme, do not meet the eligibility criteria set forth by the section of the SME loan guarantee facility under the Horizon 2020 programme, with a minimum maturity of 12 months. Beyond such limits, the proof whether the SME is eligible to the SME section of the loan guarantee facility under Horizon 2020 lies in the financial intermediaries. LGF is structured so as to allow presenting an account of the beneficiary SMEs, indicating both the number and the amounts of loans. 


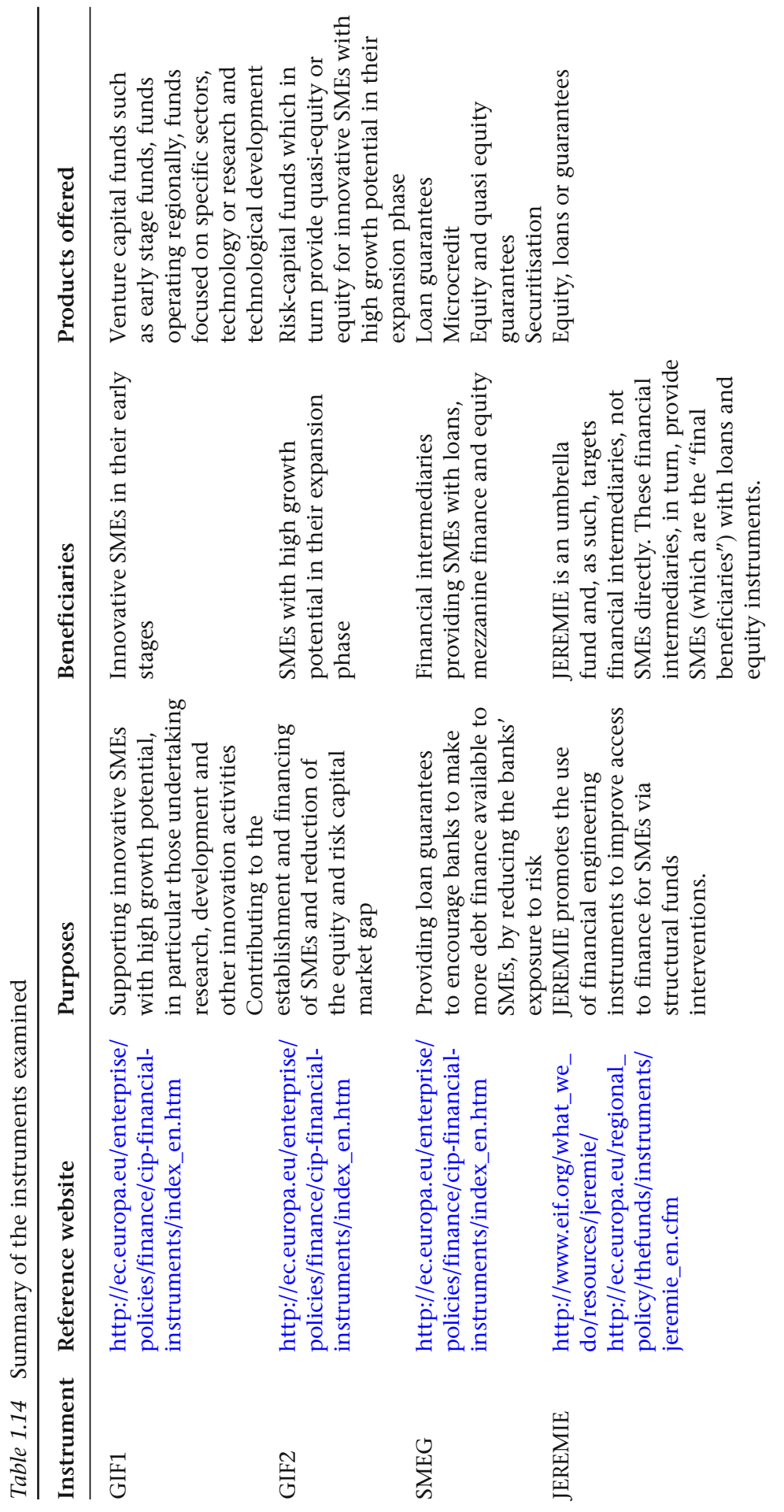




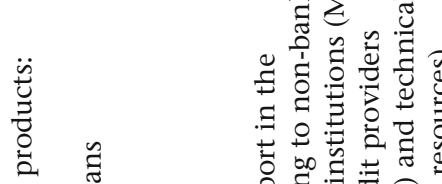

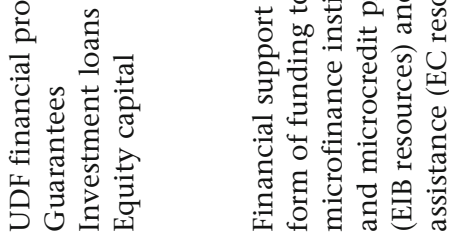

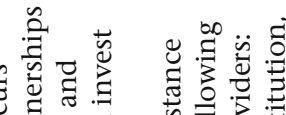

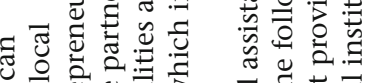

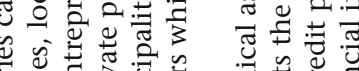

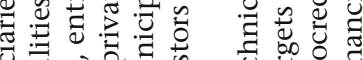
㺃:

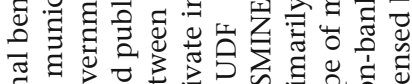

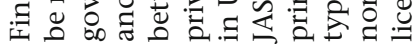

-

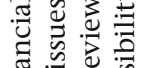

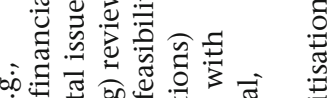

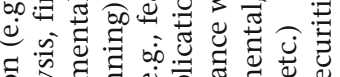

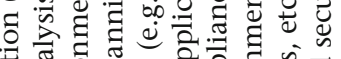

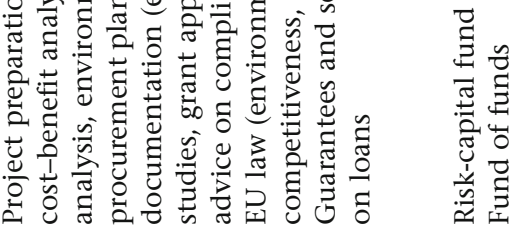

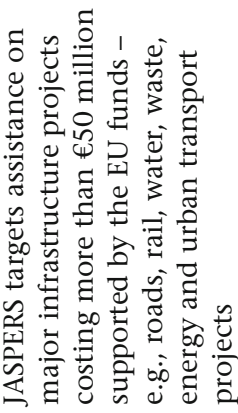

。ี

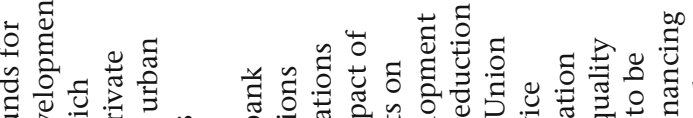

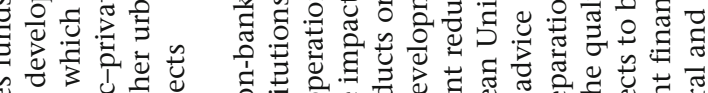

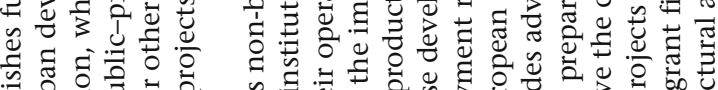

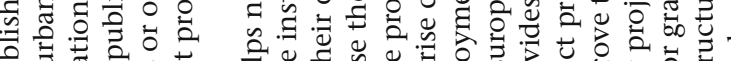

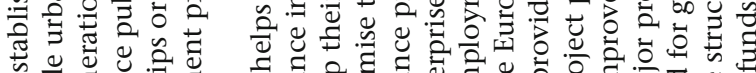

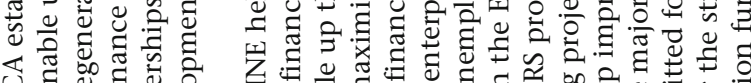

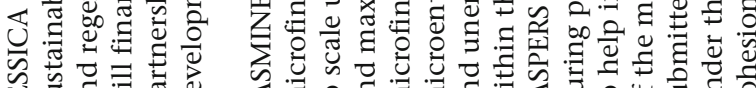

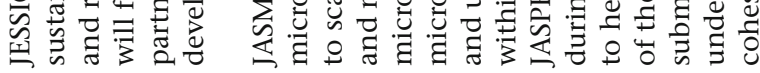

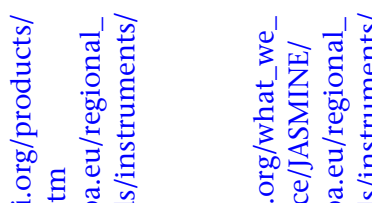

ö $\Xi$ :

政

षैं की

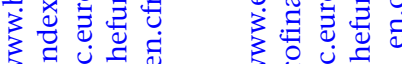

$\Xi$ ن⿺辶寸

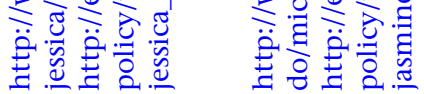

旁

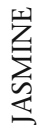

舀

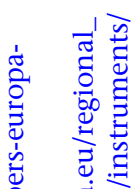

ते तें

文

bo نे है

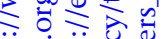

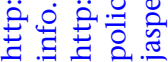

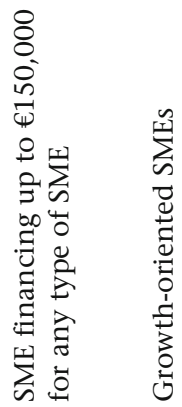

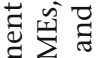

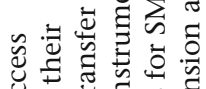
声 $\cong \cong$

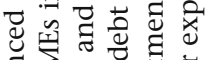
ฮี bo \& $b_{0} 0 . \Xi$

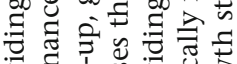

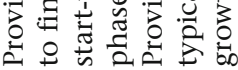

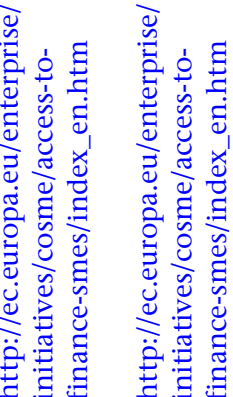

志皆

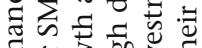




\section{Notes}

1. Although the chapter has been prepared by both authors jointly, $\S 1.1$ was written by Pasqualina Porretta, whereas $\$ \S 1.2-1.6$ were written by Francesco Minnetti and $\S \S 1.7-1.17$ by Ervin Sinani.

2. http://www.microcreditoitalia.org/index.php?lang=it.

3. http://www.microcreditoitalia.org/capacitybuilding/.

4. This definition is contained in EC Recommendation no. 1442 issued on 6 May 2003, replacing EC Recommendation no. 280 of 1996 and entered into force on 1 January 2005.

5. According to Otero $(1999$, p. 8), microfinance is "the provision of financial services to low-income poor and very poor self-employed people".

6. In the most developed businesses, instead, innovative products are usually developed within large existing organisations.

7. More precisely, flexibility consists in timely adaptation of quality, quantity and characteristics of the business, such as its seasonality, the occasional need to rely on external workers, the determination of in-progress production methods, the diversification of products and services compared to market standards and other circumstances that are typical of the so-called "nichemarkets", where small and microenterprises often operate.

8. The analysis of the American professor (Birch, 1993) - which moves from the fundamental premise that the American as well as the European economies are cyclically affected by a deep economic crisis every five years or so, which results in the replacement of 50 per cent of businesses and jobs - is deemed highly relevant as its observations are based on a large sample of businesses, something in the region of 22 million companies over a 22-year timeline, from the end of the 1960s to the 1980s.

9. This can be due to multiple factors, such as the high concentration of businesses in their territory, the start-up of new industrial activities, the opening of reference markets, development projects through acquisitions, delocalisation of production, the need to cope with various problems and trends that characterise their sectors.

10. Innovative projects that reach the stage of product marketing can, as a matter of fact, generate high operating profits for companies due to the competitive advantage obtained by those firms able to introduce new products in the market or manufacture existing products in an innovative way. However, the transition from the design and initial implementation phases to the subsequent development and marketing stages may result particular selective, as companies may decide to abandon their projects with the consequent loss of the capital invested.

11. A critical analysis of the main scientific contributions on this topic can be found in Bhattacharya and Thakor (1993), Dabrassi (1996) and Ongena and Smith (2000), among others.

12. The ten principles are the following: entrepreneurship, second chance, think small first, receptive administration, public contracts and aid, access to credit, single market, innovation and skills, environment, internationalisation. Every year, the profile of each country for each of these principles is assessed both with regard to the existing situation in the previous year and the average value recorded at EU level, in order to assess the global situation as well as identify any gap 
in order to take the necessary corrective actions. See European Commission in Enterprise and Industry topics, "Small Business Act" for Europe, 2013.

13. For access to credit, among other things, the following information must be provided: rejected applications for funding and unacceptable offers for financing; access to public financial support, including public guarantees; willingness of the banks to grant loans; relative difference in the interest rate levels between loans up to $€ 1$ million and loans of more than $€ 1$ million; investments in venture capital; UIF regional funds for entrepreneurship and SMEs; UE funds for the creation and development of enterprises.

14. The reference parameter of 2007 deliberately provides a basis for assessment prior to the beginning of the financial crisis.

15. If the index shows values lower than the 2007 reference value, it means that access to credit is lower than the years before the crisis.

16. European Central Bank (2014), "Survey on the access to finance of small and medium-sized enterprises in the euro area - October 2013 to March 2014", https://www.ecb.europa.eu/pub/pdf/other/accesstofinancesmallmediumsizedenterprises201404en.pdf?da920468528300ff549d8cc95522eb81.

17. See p. 4, 5 of the Survey SAFE (2014), April http://www.ecb.europa.eu/pub/ pdf/other/accesstofinancesmallmediumsizedenterprises201404en.pdf?da920 $468528300 \mathrm{ff} 549 \mathrm{~d} 8 \mathrm{cc} 95522 \mathrm{eb} 81$.

18. See p. 25 of the Survey SAFE (2014), April, http://www.ecb.europa.eu/pub/ pdf/other/accesstofinancesmallmediumsizedenterprises201404en.pdf?da920 $468528300 \mathrm{ff} 549 \mathrm{~d} 8 \mathrm{cc} 95522 \mathrm{eb} 81$.

19. See p. 7 Survey SAFE (2014), April, http://www.ecb.europa.eu/pub/pdf/other/ accesstofinancesmallmediumsizedenterprises201404en.pdf?da92046852830 Off549d8cc95522eb81.

20. See European Commission, 2013 SMEs' access to finance survey, p. 19, 20, http://ec.europa.eu/enterprise/policies/finance/files/2013-safe-analyticalreport_en.pdf.

21. See p. 16 of the SAFE, April survey, http://www.ecb.europa.eu/pub/pdf/other/ accesstofinancesmallmediumsizedenterprises201404en.pdf?da92046852830 Off549d8cc95522eb81.

22. European Commission (2013), 2013 SMEs' access to finance survey - analytical report, http://ec.europa.eu/enterprise/policies/finance/files/2013-safeanalytical-report_en.pdf.

23. European Commission (2013), One out of three SMEs did not get the finance they needed in 2013, Brussels, http://europa.eu/rapid/pressrelease_IP-13-1070_en.htm.

24. Further details of the interviewing methods, sampling and weights applied can be found in appendix 1, http://ec.europa.eu/enterprise/policies/finance/ files/2013-safe-analytical-report_en.pdf.

25. The sample was selected following random criteria, albeit in a disproportionate manner and according to the following criteria:

- Countries: $28 \mathrm{EU}$ member countries and other countries participating in the Entrepreneurship and Innovation programme (EIP).

- Enterprise size: micro (1-9 employees), small (10-49 employees), mediumsized (50-249 employees) and large (over 250 employees) enterprises.

The enterprises surveyed operate in the following sectors: mining and quarrying; manufacturing; electricity; gas and water; construction; wholesale and 
retail business; hotels and restaurants; transport, storage and communication; real estate; rental and trade; education; health-care and other social services; other public, social and personal services. Source: European Commission (2013), 2013 SMEs' access to finance survey - analytical report, http://ec.europa. eu/enterprise/policies/finance/files/2013-safe-analytical-report_en.pdf.

26. The survey carried out covers multiple periods of time. In particular, June to July 2009, August to October 2011 and August to October 2013.

27. http://ec.europa.eu/cip/index_en.htm.

28. European Parliament (2006), Decision no. 1639/2006/CE of the European Parliament and of the Council of 24 October 2006 establishing a Competitiveness and Innovation Framework Programme (2007-2013), Official Journal of the European Union, http://eur-lex.europa.eu/LexUriServ/LexUriServ. do?uri=OJ:L:2006:310:0015:0040:en:PDF.

29. http://ec.europa.eu/enterprise/initiatives/cosme/index_en.htm.

30. http://www.eib.org/.

31. http://eur-lex.europa.eu/legal-content/EN/TXT/PDF/?uri=OJ:C:2010:083:FU LL\&from=IT, Official Journal of the European Union, C83, 30 March 2010, art. 309, TFUE, p. 182.

32. European Union (2010), "Consolidated versions of the treaty on European Union and the treaty on the functioning of the European Union, Official Journal of the European Union, C83, 30 March, art. 17, http://eur-lex.europa. eu/legal-content/EN/TXT/PDF/?uri=OJ:C:2010:083:FULL\&from=IT; http:// eur-lex.europa.eu/legal-content/IT/TXT/PDF/?uri=OJ:C:2010:083:FULL\&fro $\mathrm{m}=\mathrm{IT}$, Official Journal of the European Union, C83, 30 March 2010, protocol no. 5, BEI General Statute, art. 17, p. 261.

33. Ibid., art. 22, p. 264.

34. http://www.eif.org/.

35. http://eur-lex.europa.eu/LexUriServ/LexUriServ.do?uri=OJ:L:2006:310:0015: 0040:en:PDF, art. 3.

36. European Parliament (2006), Decision no. 1639/2006/CE of the European Parliament and of the Council of 24 October 2006, establishing a Competitiveness and Innovation Framework Programme (2007-2013), Official Journal of the European Union, art. 18, http://eurlex.europa.eu/ LexUriServ/LexUriServ.do?uri=OJ:L:2006:310:0015:0040:en:PDF.

37. European Commission (2006), "CIP financial instruments, entrepreneurship and Innovation Programme", http://eur-lex.europa.eu/LexUriServ/ LexUriServ.do?uri=OJ:L:2006:310:0015:0040:IT:PDF.

38. European Parliament (2006), Decision no. 1639/2006/CE of the European Parliament and of the Council of 24 October 2006 establishing a Competitiveness and Innovation Framework Programme (2007-2013), Official Journal of the European Union, 22, http://eur-lex.europa.eu/LexUriServ/ LexUriServ.do?uri=OJ:L:2006:310:0015:0040:en:PDF.

39. Ibid., art. 18, p. 25.

40. "Asset stripping" is defined as the process of buying an undervalued company with the intent to sell off its assets for a profit.

41. European Commission (2013), Entrepreneurship and Innovation Programme Committee, p. 7, http://ec.europa.eu/cip/files/cip/eip_performance_report_ 2007-2013_en.pdf.

42. Ibid. 
43. European Parliament (2006), Decision no. 1639/2006/EC of the European Parliament and of the Council of 24 October 2006 establishing a Competitiveness and Innovation Framework Programme (2007-2013), Official Journal of the European Union, art. 19, p. 26, http://eur-lex.europa.eu/ LexUriServ/LexUriServ.do?uri=OJ:L:2006:310:0015:0040:en:PDF.

44. European Parliament (2006), Decision no. 1639/2006/EC of the European Parliament and of the Council of 24 October 2006 establishing a Competitiveness and Innovation Framework Programme (2007-2013), Official Journal of the European Union, art. 20, p. 26, http://eur-lex.europa.eu/ LexUriServ/LexUriServ.do?uri=OJ:L:2006:310:0015:0040:en:PDF.

45. http://ec.europa.eu/regional_policy/archive/themes/financial/ index_en.htm.

46. As part of an operational programme, the structural funds may finance expenditure with respect to an operation comprising contributions to support any of the following:

a) financial engineering instruments for enterprises, esp. for small and medium-sized enterprises, such as venture capital funds, guarantee funds and loan funds;

b) urban development funds, i.e., funds investing in public-private partnerships and other projects included in an integrated plan for sustainable urban development;

c) funds or other incentive schemes providing loans, guarantees for repayable investments or equivalent instruments for energy efficiency and use of renewable energy sources in building, including in existing housing.

When such operations are organised through holding funds, i.e., funds set up to invest in different venture capital funds, guarantee funds, loan funds, urban development funds, funds or other support programmes that grant loans, guarantees for repayable investments or similar instruments for energy efficiency and the use of renewable energy sources in building, including in the existing residential buildings, the member states or the managing authority shall implement them through one or more of the following forms:

a) the award of a public contract in accordance with applicable public procurement law;

b) in other cases, where the agreement is not a public service contract within the meaning of public procurement law, the award of a grant, defined for this purpose as a direct financial contribution by way of donation to a financial institution without a call for proposals, if this is in accordance with a national law compatible with the treaty;

c) the award of a contract directly to the EIB or the EIF.

European Council (2006), Council Regulation (EC) no. 1083/2006 of 11 July 2006 - laying down general provisions on the European Regional Development Fund, the European Social Fund and the Cohesion Fund and repealing regulation (EC) no. 1260/1999, Official Journal of the European Union, http://eur-lex.europa.eu/LexUriServ/LexUriServ.do?uri=OJ:L:2006: 210:0025:0078:EN:PDF.

47. European Investment Fund (2012), "JEREMIE - a new way of using EU structural funds to promote SME access to finance via Holding Funds", Luxembourg, http://www.eif.org/news_centre/publications/Jeremie_leaflet_files/ jeremie_leaflet_en.pdf. 
48. Commission of the European Communities (2006), "Communication from the Commission to the Council, the European parliament, the European Economic and Social Committee and the Committee of the Regions - implementing the Community Lisbon Programme: Financing SME growth adding European value", COM (2006) 349 final, http://eur-lex.europa.eu/ legal-content/EN/TXT/PDF/?uri=CELEX:52006DC0349\&qid=140370256926 $7 \&$ from $=\mathrm{EN}$.

49. The contributions of the European Regional Development Fund (ERDF) are allocated to urban development funds (UDF), which, in turn, invest them in public-private partnerships or other projects included in an integrated plan for sustainable urban development. These investments can take the form of equity, loans and/or guarantees.

50. European Investment Bank (2008), "JESSICA - a new way of using EU funding to promote sustainable investments and growth in urban areas", Luxembourg, http://www.eib.org/attachments/thematic/jessica_2008_it.pdf.

51. An integrated plan for urban sustainable development is a system of interconnected interventions aimed at steadily improving economic, physical, social and environmental conditions of urban areas.

52. The $N+2$ rule is referred to the automatic decommissioning of resources as governed by art. 93 of regulation no. 1083 of 2006. In particular, paragraph 1 of the regulation at issue states, "The Commission shall automatically decommission any part of a commitment included in an Operational Plan which has not been settled by the payment on account or for which it has not received an acceptable payment application pursuant art. 86, by the end of the second year following the year of commitment or, where appropriate, for the amounts concerned pursuant paragraph 2". http://eur-lex.europa.eu/ LexUriServ/LexUriServ.do?uri=OJ:L:2006:210:0025:0078:EN:PDF.

53. http://www.jaspers-europa-info.org/.

54. European Investment Bank (2012), "JASPERS - European Investment Bank", Luxembourg, http://www.jaspers-europa-info.org/attachments/article/123/ JASPERS\%20brochure\%202012.pdf.

55. http://ec.europa.eu/regional_policy/thefunds/instruments/jaspers_en.cfm.

56. http://ec.europa.eu/regional_policy/thefunds/instruments/jasmine_en.cfm.

57. Commission of the European Communities (2007), "Communication from the Commission to the Council, the European Parliament, the European Economic and Social Committee and the Committee of the Regions - a European initiative for the development of microcredit in support of growth and employment", COM (2007) 708 final, http://eur-lex.europa.eu/legalcontent/EN/TXT/PDF/?uri=CELEX:52007DC0708\&qid=1403707249640\&fro $\mathrm{m}=\mathrm{EN}$.

58. The economic self-sustainability of a credit agency is its capacity to break away from the initial donations through which it starts its own business.

59. MicroFinanza Rating (MFR) is a private and independent international rating agency, specialising in microfinance, founded in 2000. Its mission is to provide the microfinance and responsible finance industry with independent, high quality ratings and information services aiming at enhancing transparency, facilitating investments and promoting best practices worldwide. http://www.microfinanzarating.com/index.php?option=com_content \&view=article\&id=97\&Itemid=167\&lang=en. 
60. Planet Rating is a specialised microfinance rating agency offering evaluation and rating services to microfinance institutions (MFIs), using the Smart GIRAFE and the Social Performance methodologies. http://www.planetrating. com/EN/who-are-we-a.html.

61. http://www.eif.org/what_we_do/microfinance/JASMINE/.

62. http://ec.europa.eu/regional_policy/thefunds/instruments/doc/summary_ data_fei_2012.pdf.

63. Specific funds set up according to Art. $44 \S 1$ a), Art. $44 \S 1$ b) and Art. $44 \S 1$ c) of the General Regulation no. 1083/2006. http://eur-lex.europa.eu/legalcontent/EN/TXT/PDF/?uri=CELEX:32006R1083\&from=EN.

64. http://ec.europa.eu/enterprise/initiatives/cosme/index_en.htm.

65. European Parliament, European Council (2013), Regulation (EU) no. 1287/2013 of the European Parliament and of the Council of 11 December 2013 establishing a Programme for the Competitiveness of Enterprises and small and medium-sized enterprises (COSME) (2014-2020) and repealing Decision no. 1639/2006/EC, Official Journal of the European Union, art. 5, http://eur-lex.europa.eu/legal-content/EN/TXT/PDF/?uri=CELEX:32013R12 $87 \& q i d=1401115426118 \&$ from $=$ IT.

66. http://ec.europa.eu/enterprise/policies/finance/risk-capital/business-angels/ index_en.htm.

67. European Parliament, European Council (2013), Regulation (EU) no $1287 / 2013$ of the European Parliament and of the Council of 11 December 2013 establishing a Programme for the Competitiveness of Enterprises and small and medium-sized enterprises (COSME) (2014-2020) and repealing Decision no. 1639/2006/EC, Official Journal of the European Union, art. 18, p. 43, http://eur-lex.europa.eu/legal-content/EN/TXT/PDF/?uri=CELEX:3201 3R1287\&qid=1401115426118\&from=IT.

68. Ibid., art. 19, p. 43.

(c) (i) Except where otherwise noted, this work is licensed under a a copy of this license, visit http://creativecommons.org/licenses/by/3.0/ 